\title{
The Relationship between Age, Neural Differentiation, and Memory Performance
}

\author{
ㄱoshua D. Koen, ${ }^{1,2,3}$ Nedra Hauck, ${ }^{2}$ and ${ }^{\oplus}$ Michael D. Rugg ${ }^{2,3,4}$ \\ ${ }^{1}$ Department of Psychology, University of Notre Dame, Notre Dame, Indiana 46556, ${ }^{2}$ Center for Vital Longevity, University of Texas at Dallas, Dallas, Texas \\ $75235,{ }^{3}$ chool of Behavioral and Brain Sciences, University of Texas at Dallas, Richardson, Texas 75080, and ${ }^{4}$ University of Texas Southwestern Medical \\ Center, Dallas, Texas 75390
}

\begin{abstract}
Healthy aging is associated with decreased neural selectivity (dedifferentiation) in category-selective cortical regions. This finding has prompted the suggestion that dedifferentiation contributes to age-related cognitive decline. Consistent with this possibility, dedifferentiation has been reported to negatively correlate with fluid intelligence in older adults. Here, we examined whether dedifferentiation is associated with performance in another cognitive domain - episodic memory-that is also highly vulnerable to aging. Given the proposed role of dedifferentiation in age-related cognitive decline, we predicted there would be a stronger link between dedifferentiation and episodic memory performance in older than in younger adults. Young ( $18-30$ years) and older (64-75 years) male and female humans underwent fMRI scanning while viewing images of objects and scenes before a subsequent recognition memory test. We computed a differentiation index in two regions of interest (ROIs): parahippocampal place area (PPA) and lateral occipital complex (LOC). This index quantified the selectivity of the BOLD response to preferred versus nonpreferred category of an ROI (scenes for PPA, objects for LOC). The differentiation index in the PPA, but not the LOC, was lower in older than in younger adults. Additionally, the PPA differentiation index predicted recognition memory performance for the studied items. This relationship was independent of and not moderated by age. The PPA differentiation index also predicted performance on a latent "fluency" factor derived from a neuropsychological test battery; this relationship was also age invariant. These findings suggest that two independent factors, one associated with age, and the other with cognitive performance, influence neural differentiation.
\end{abstract}

Key words: dedifferentiation; lateral occipital complex; neural selectivity; older adults; parahippocampal place area; recognition memory

Significance Statement

Aging is associated with neural dedifferentiation—reduced neural selectivity in "category-selective" cortical brain regionswhich has been proposed to contribute to cognitive aging. Here, we examined whether neural differentiation is predictive of episodic memory performance, and whether the relationship is moderated by age. A neural differentiation index was estimated for scene-selective (PPA) and object-selective (LOC) cortical regions while participants studied images for a subsequent memory test. Age-related reductions were observed for the PPA, but not for the LOC, differentiation index. Importantly, the PPA differentiation index demonstrated age-invariant correlations with subsequent memory performance and a fluency factor derived from a neuropsychological battery. Together, these findings suggest that neural differentiation is associated with two independent factors: age and cognitive performance.

\section{Introduction}

Healthy aging is accompanied by numerous structural (Raz et al., 2005) and functional (Spreng et al., 2010) brain changes believed to contribute to age-related cognitive decline (Raz and Rodrigue,

Received June 12, 2018; revised 0ct. 21, 2018; accepted 0ct. 23, 2018.

Author contributions: J.D.K., N.H., and M.D.R. designed research; J.D.K. and N.H. performed research; J.D.K. analyzed data; J.D.K. and M.D.R. wrote the paper.

The research was supported by National Institute on Aging Grants AG039103 (to M.D.R.) and AG049583 (to J.D.K.), and a fellowship from the Aging Mind Foundation (to J.D.K.). This research was completed while J.D.K. was at the University of Texas at Dallas.

The authors declare no competing financial interests.
2006). Of relevance here is research demonstrating that increasing age is associated with reduced neural differentiation or reduced selectivity of cortical regions sensitive to a specific class of stimuli (Park et al., 2004). Age-related neural dedifferentiation has been most commonly identified in the ventral visual cortex (Grady et al., 1994; Park et al., 2004, 2010, 2012; Chee et al., 2006; Payer et al., 2006; Voss et al., 2008; Carp et al., 2011b; Kleemeyer

Correspondence should be addressed to Joshua D. Koen, Department of Psychology, University of Notre Dame, 390 Corbett Family Hall, Notre Dame, IN 46556. E-mail: jkoen@nd.edu.

https://doi.org/10.1523/JNEUROSCI.1498-18.2018

Copyright $\odot 2019$ the authors $\quad 0270-6474 / 19 / 390149-14 \$ 15.00 / 0$ 


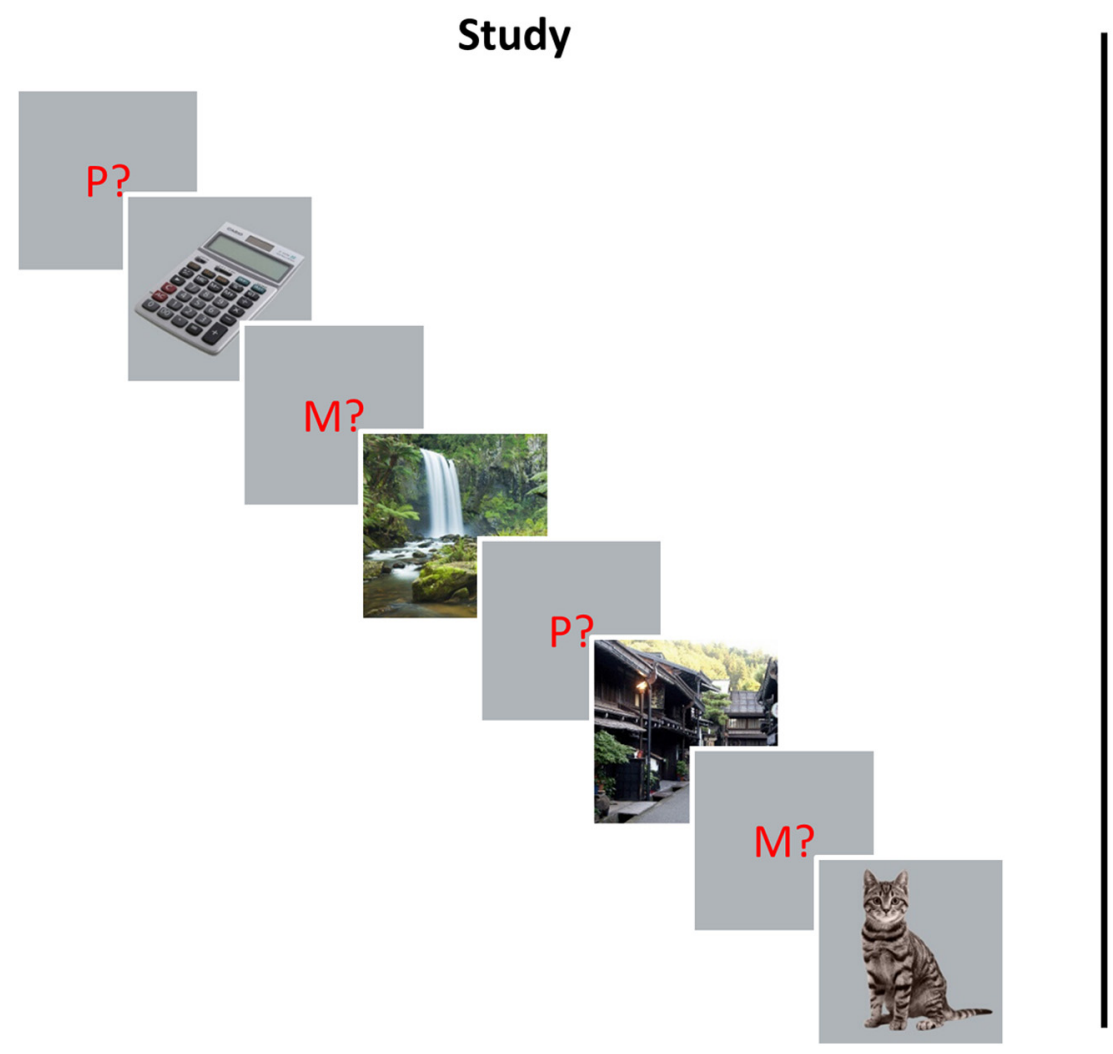

Test

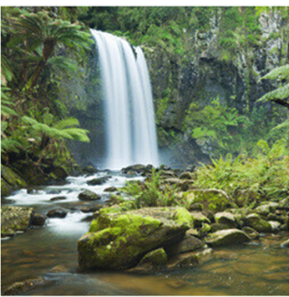

$\begin{array}{ccc}\text { Old } & \text { Old } & \text { Old } \\ \text { Pleasant } & \text { Movie } & \text { Don't Know }\end{array}$

Figure 1. Schematic overview of the memory task. Participants studied an intermixed list of object and scene images under intentional encoding instructions while undergoing fMRI scanning. Each image was preceded by a task cue that instructed participants to rate the image for pleasantness (P?) or to determine which movie genre the image was best associated with (M?). There was a total of five scanned study phases. After the final study phase, an out-of-scanner recognition memory test was administered. The test phase comprised the studied objects and scenes intermixed with new images. Participants were instructed to select one of four memory judgments for each image. The four judgments comprised options for whether participants had high confidence both that they studied the image and could recollect the study task (Old Pleasant and Old Movie responses), had high confidence that they studied the image but were had low confidence in their memory for or could not remember the study task (Old-Don't Know response), or whether they did not have high confidence that the image was studied (New response). Two measures of memory performance were obtained from the test phase: item recognition and recall of the encoding task (i.e., source recall).

et al., 2017; also see Berron et al., 2018), although the pattern has also been observed in auditory cortex (Du et al., 2016) and motor cortex (Carp et al., 2011a). Neural dedifferentiation is believed to play an important role in cognitive aging ( $\mathrm{Li}$ et al., 2001; Li and Sikström, 2002; Goh, 2011). Consistent with this proposal, measures of neural dedifferentiation have been reported to correlate negatively with cognitive performance in healthy older adults (Park et al., 2010; Du et al., 2016).

Here, we examine the proposal that neural dedifferentiation contributes to age differences in episodic memory (St-Laurent et al., 2014; Zheng et al., 2018). Healthy aging is associated with disproportionate reductions in the ability to recollect details about past events (for review, see Koen and Yonelinas, 2014; Schoemaker et al., 2014), and this deficit is largely attributed to reduced efficacy of encoding processes (Craik, 1986; Craik and Rose, 2012; Friedman and Johnson, 2014). Prior work investigating the relationship between neural dedifferentiation and memory encoding has focused on the fidelity of neural patterns across repeated instances of a given item within a stimulus category (St-Laurent et al., 2014; Zheng et al., 2018). The results from these studies are mixed as to whether neural dedifferentiation during encoding might contribute to age differences in memory performance. Here, we focus on indices of neural dedifferentiation measured across different stimulus categories (i.e., objects and scenes; Park et al., 2004) during memory encoding, and whether these indices predict subsequent memory performance.
Participants encoded images of objects and scenes for a subsequent memory test while undergoing fMRI (Fig. 1). Objects and scenes were selected as stimuli because they selectively engage distinct cortical regions in the ventral visual cortex. Specifically, relative to scenes, viewing images of single objects engages the lateral occipital complex (LOC; Grill-Spector et al., 2001). In contrast, viewing images of scenes activates posterior parahippocampal and adjacent fusiform cortex-the "parahippocampal place area" (PPA; Epstein and Kanwisher, 1998). We examined age differences in neural differentiation with a differentiation index computed from individual trial blood oxygenation leveldependent (BOLD) responses to objects and scenes in the LOC and PPA (Voss et al., 2008). This index reflects the scaled difference between the BOLD response of a region of interest (ROI) to a preferred (e.g., scenes in the PPA) and not preferred (e.g., objects in the PPA) stimulus category (see Materials and Methods). In a complementary analysis, neural differentiation was also examined with multivoxel pattern analysis (e.g., Carp et al., 2011b). We examined the relationship between neural differentiation and two measures of memory performance, namely item recognition and source recall. Our prediction was that higher values of neural differentiation, which are indicative of increased levels of neural selectivity (Voss et al., 2008), would predict higher performance on a subsequent memory test by virtue of the mnemonic benefit associated with encoding relatively distinctive information (Murdock, 1960; Lockhart et al., 1976; Hunt, 1995). Like prior 
research (Park et al., 2010), we also examined whether neural differentiation was associated with neuropsychological test performance. If neural dedifferentiation contributes disproportionately to memory performance (and, perhaps, performance in other cognitive domains) in older adults, differentiation should be more strongly correlated with performance in older relative to younger participants.

\section{Materials and Methods}

Ethics statement

The Institutional Review Board of the University of Texas at Dallas approved the experimental procedures described below. All participants provided written informed consent before participation.

\section{Experimental design and statistical analysis}

As will be elaborated in the remainder of the Materials and Methods, the main independent variables in this experiment included age group (young vs older), image type (scene vs object), and region of interest (PPA vs LOC). Results from all analyses were considered significant at $p<0.05$.

Statistical analyses were conducted with $R$ software (R Core Team, 2017). ANOVAs were conducted using the afex package (Singmann et al., 2016), and the Greenhouse and Geisser (1959) procedure was used to correct the degrees of freedom for nonsphericity in the ANOVAs when necessary. Post hoc tests on significant effects from the ANOVAs were conducted using the lsmeans package (Lenth, 2016) with degrees of freedom estimated using the approximation of Satterthwaite (1946). Effect size measures for results from the ANOVAs are reported as partial $\eta^{2}$ (Cohen, 1988). Linear regression models were implemented using the $\mathrm{lm}$ function in the base $R$ library. Principal components analysis (PCA; Hotelling, 1933; Abdi and Williams, 2008) was conducted using the psych package (Revelle, 2017).

\section{Participants}

A sample of 24 young and 24 older participants contributed to the data reported here. Participants were recruited from the University of Texas at Dallas and the greater Dallas metropolitan area, and received monetary compensation $(\$ 30 / \mathrm{h})$. Table 1 reports participant demographics and neuropsychological test performance. All participants were right handed and reported having normal or corrected-to-normal vision and no contraindications to MRI scanning. Exclusion criteria included a history of cardiovascular disease (other than treated hypertension), diabetes, psychiatric disorder, illness, or trauma affecting the CNS, substance abuse, and self-reported current or recent use of psychotropic medication or sleeping aids. All participants scored $\geq 27$ on the Mini-Mental State Examination (Folstein et al., 1975) and scored within the normal range for their age group on a battery of neuropsychological tests.

Data from an additional four participants were excluded from the analyses reported here for the following reasons: one young adult male and one older adult male were excluded due to excessive in-scanner motion ( $>8 \mathrm{~mm}$ frame displacement), and two older adult males were excluded for providing two or fewer source correct trials (see below).

Many participants in the present study participated in prior studies reported by our laboratory. Specifically, 18 young ( 10 females) and 16 older (4 females) persons participated in an event-related potential study reported by Koen et al. (2018). Additionally, two older adults (one female) participated in a prior fMRI experiment reported by de Chastelaine et al. (2016).

\section{Neuropsychological test battery}

Participants completed a neuropsychological test battery on a separate day before the fMRI study. The battery included the Mini-Mental State Examination, California Verbal Learning Test-II (CVLT; Delis et al., 2000), the symbol digit modalities test (SDMT; Smith, 1982), forward and backward digit span subtests of the Wechsler Adult Intelligence Scale-Revised (Wechsler, 1981), trail-making tests A and B (Reitan and Wolfson, 1985), the F-A-S subtest of the Neurosensory Center Comprehensive Evaluation for Aphasia (Spreen and Benton, 1977), the category fluency test for animals (Benton, 1968), Wechsler test of adult reading
Table 1. Demographic and neuropsychological test data for young and older adults

\begin{tabular}{|c|c|c|c|}
\hline & Young adults & Older adults & $p$ value \\
\hline$N$ & 24 & 24 & \\
\hline Age (years) & $23.04(3.46)$ & $68.92(3.23)$ & \\
\hline $\operatorname{Sex}(M / F)$ & $12 / 12$ & $12 / 12$ & \\
\hline Education & $15.92(2.22)$ & $17.12(2.23)$ & 0.067 \\
\hline MMSE & $29.54(0.59)$ & $29.42(0.93)$ & 0.581 \\
\hline CVLT short delay-free & $13.08(1.79)$ & $10.83(2.84)$ & 0.002 \\
\hline CVLT short delay-cued & $13.67(1.81)$ & $12.33(2.32)$ & 0.032 \\
\hline CVLT Long delay-free & $13.54(2.06)$ & $10.71(2.91)$ & $<0.001$ \\
\hline CVLT long delay-cued & $14.12(1.62)$ & $12.33(2.46)$ & 0.005 \\
\hline CVLT recognition-hits & $15.42(0.83)$ & $15.04(1.00)$ & 0.164 \\
\hline CVLT recognition-false alarms & $0.46(0.66)$ & $2.67(2.08)$ & $<0.001$ \\
\hline Logical memory I & $30.62(4.95)$ & $26.71(5.09)$ & 0.010 \\
\hline Logical memory II & $28.12(5.78)$ & $23.25(5.72)$ & 0.005 \\
\hline Digit span total ${ }^{1}$ & $21.04(4.53)$ & $17.58(2.41)$ & 0.002 \\
\hline SDMT & $65.38(13.99)$ & $47.21(7.53)$ & $<0.001$ \\
\hline Trails A (s) & $21.43(7.97)$ & $30.76(10.77)$ & 0.001 \\
\hline Trails B (s) & $47.54(19.53)$ & $69.11(24.64)$ & 0.002 \\
\hline F-A-S total & $48.29(10.97)$ & $45.96(11.65)$ & 0.479 \\
\hline Category fluency (Animals) & $24.58(5.67)$ & $21.08(4.82)$ & 0.026 \\
\hline WTAR (Raw) & $41.42(3.44)$ & $43.62(4.44)$ & 0.061 \\
\hline Raven's (List 1) & $11.08(0.97)$ & $9.50(2.23)$ & 0.003 \\
\hline Visual acuity (logMar) ${ }^{2}$ & $-0.11(0.10)$ & $0.06(0.11)$ & $<0.001$ \\
\hline Speed factor $(\mathrm{RC} 1)^{3}$ & $-0.64(0.67)$ & $0.33(0.75)$ & $<0.001$ \\
\hline Memory factor (RC2) & $0.55(0.73)$ & $-0.62(1.00)$ & $<0.001$ \\
\hline Crystallized intelligence factor (RC3) & $0.00(0.79)$ & $0.08(0.93)$ & 0.751 \\
\hline Fluency factor (RC4) & $0.07(0.89)$ & $-0.21(0.72)$ & 0.257 \\
\hline
\end{tabular}

SDs are reported in parentheses. The $p$ values were obtained from Welch's $t$ test comparing young and older adults. MMSE, Mini-Mental State Examination; M, male; F, female.

${ }^{1}$ Digit span total equals the sum of forward and backward span.

${ }^{2}$ Lower logMAR scores indicate better visual acuity.

${ }^{3}$ Negative factors on the speed factor (RC1) correspond to higher performance on measures of processing speed (e.g., shorter time to complete trails A or B), whereas for other factors higher performance is indicated by higher scores.

(WTAR; Wechsler, 2001), the logical memory subtest of the Wechsler Memory Scale (Wechsler, 2009), and List 1 of the Raven's Progressive Matrices (Raven et al., 2000). Volunteers were excluded from participating in the fMRI study if (1) one or more of the memory measures (i.e., CVLT or logical memory) were $>1.5$ SDs below the age- and educationadjusted mean, (2) they had a standard score of $<100$ on the WTAR, or (3) two or more scores on nonmemory tests were 1.5 SDs below the mean (see below for the dependent measures that were used).

\section{Neuropsychological data analysis}

The scores on the neuropsychological test battery were reduced to factor scores based on PCA applied to a prior dataset from our laboratory that included young, middle, and older adults (de Chastelaine et al., 2016). Principal components with eigenvalues $>1$ were kept and rotated using Varimax rotation (Kaiser, 1958). The following variables were included in the PCA model: CVLT composite recall measure (i.e., average number of words recalled on the short- and long-delay free- and cued-recall tests), the number of CVLT recognition hits, the number of CVLT recognition false alarms, a logical memory composite recall measure (i.e., average of immediate and delayed recalls), the completion time for both trails A and B, the number of valid responses on the SDMT, F-A-S, and Raven's, and estimated full-scale intelligence quotient derived from the WTAR. The first four components were retained and explained $64.1 \%$ of the variance in the data before rotation. The rotated components (RCs) broadly correspond to factors representing processing speed (RC1), memory (RC2), crystallized intelligence (RC3), and fluency (RC4). The weights for the rotated factors from this prior dataset are shown in Table 2. These weights were applied to the identical variables in the present dataset to extract factor scores for the analyses reported here.

\section{Visual acuity assessment}

Participants completed a visual acuity test using ETDRS charts (Precision Vision) during the neuropsychological test session. Visual acuity was 


\begin{tabular}{|c|c|c|c|c|}
\hline & $\begin{array}{l}\text { Speed } \\
\text { (RC1) }\end{array}$ & $\begin{array}{l}\text { Memory } \\
\text { (RC2) }\end{array}$ & $\begin{array}{l}\text { Crystallized } \\
\text { intelligence (RC3) }\end{array}$ & $\begin{array}{l}\text { Fluency } \\
\text { (RC4) }\end{array}$ \\
\hline CVLT composite & -0.19 & 0.84 & 0.08 & -0.15 \\
\hline CVLT hits & -0.20 & 0.42 & 0.23 & -0.64 \\
\hline CVLT false alarms & 0.21 & -0.69 & 0.26 & -0.17 \\
\hline Logical memory composite & 0.10 & 0.67 & 0.18 & 0.02 \\
\hline Trails A & 0.91 & -0.09 & -0.05 & -0.14 \\
\hline Trails B & 0.85 & -0.09 & -0.28 & 0.08 \\
\hline SDMT & -0.59 & 0.40 & 0.08 & 0.30 \\
\hline Digit span & -0.16 & 0.01 & 0.80 & -0.08 \\
\hline Category fluency (animals) & -0.34 & 0.23 & 0.14 & 0.63 \\
\hline F-A-S & -0.12 & 0.06 & 0.46 & 0.57 \\
\hline WTAR (full-scale intelligence) & -0.12 & 0.12 & 0.79 & 0.21 \\
\hline Raven's (list 1) & -0.33 & 0.48 & 0.10 & 0.05 \\
\hline Eigenvalue & 3.65 & 1.70 & 1.28 & 1.06 \\
\hline \% Variance (before rotation) & 0.20 & 0.14 & 0.11 & 0.09 \\
\hline \% Variance (after rotation) & 0.19 & 0.19 & 0.15 & 0.11 \\
\hline
\end{tabular}

measured separately for the left and right eyes, as well as with both eyes using the logMAR metric (Ferris et al., 1982; Bailey and Lovie-Kitchin, 2013). A different eye chart was used for each of the three tests. Participants prescribed corrective lenses wore them during the visual acuity test. Note that only the results from the visual acuity measured with both eyes is reported (Table 1 ).

\section{Materials and apparatus}

Stimuli were presented using Cogent 2000 software (www.vislab.ucl.ac. uk/cogent_2000.php) implemented in Matlab 2011b (www.mathworks. com). Stimuli in the scanned study phases were projected to a screen mounted at the rear of the magnet bore and viewed through a mirror mounted on the head coil. Responses during the study sessions were entered using two four-button MRI-compatible response boxes (one for each hand). The test phase was completed on a laptop computer outside the scanner. The monitor resolution setting for both the study and test phases was set at $1024 \times 768$ pixels. All stimuli were presented on a gray background (RGB values of 102, 101, and 99).

The critical stimuli comprised 360 images obtained from a variety of internet sources. Half of the images were pictures of scenes, and the remaining half were pictures of common objects. The 180 scenes comprised 90 rural (i.e., natural) scenes and 90 urban (i.e., manmade) scenes. The scenes contained objects (e.g., trees, cars, buildings), and we attempted to minimize overlap between the objects depicted in the scenes and the object images. The scenes were scaled and cropped to $256 \times 256$ pixels.

The 180 objects comprised 90 images of natural objects (e.g., food items, animals, plants) and 90 images of manmade objects (e.g., tools, vehicles, furniture). The object images were overlaid and centered on a light gray background (RGB values of 175,180 , and 184) with dimensions of $256 \times 256$ pixels. Note that the background color for the object images differed from the background of the monitor. The purpose of this was to approximately equate the area of the monitor subtended by the object and scene images.

The above-described images were used to create 24 stimulus sets that were yoked across young and older participants. Each stimulus set comprised a random selection of 120 objects and 120 scenes that served as study items. The 120 images of each type were divided into five groups of 24 , and each group was randomly assigned to one of the five scanned study phases. Half of the objects and scenes in each study session were assigned to each of the two different possible judgments in the study phase (Pleasantness and Movie; see below). The test stimuli comprised all the images from the study phase along with the remaining 60 objects and 60 scenes, which served as new items. All stimulus lists were pseudorandomized such that there were no more than three consecutive presentations of objects or scenes and no more than three consecutive Pleasantness or Movie judgments.
An additional 16 objects and 16 scenes with similar characteristics to those described above served as practice stimuli. The images in each practice list were the same for all participants. There were three practice study lists (self-paced, speeded, real; see below), each comprising eight images (four objects, four scenes). A practice test list was also created and comprised the images from the speeded and real practice study phases (old items) and eight images (four objects, four scenes) as new items.

\section{Procedure}

Overview. The experiment was completed across two sessions on different days, with the neuropsychological test battery completed in the first session, and the experimental fMRI session completed in the second session. In the fMRI session, participants first completed a face-viewing task in which they pressed a button when an inverted face appeared among a sequence of upright faces. The face-viewing task is not discussed further here and will be the subject of a separate report. Following the face-viewing task, participants completed the study phase of the experiment described here, followed by a test phase administered outside of the scanner (Fig. 1).

Study phase. Participants completed the study phase during five consecutive fMRI scanning sessions. The study phase was completed under intentional encoding conditions with specific reference to the nature of the subsequent memory test.

The sequence and timing for each trial was as follows: get ready signal (green fixation cross for $500 \mathrm{~ms}$ ), task cue (red “P?" or “M?” for $500 \mathrm{~ms}$ ), study image (object or scene for $2000 \mathrm{~ms}$ ), and white fixation $(1750 \mathrm{~ms}$ ). The task cue informed participants which one of two judgments they should make about the following image. Images preceded by a P? (Pleasantness) required participants to rate how pleasant they found the image using the following scale: "Very," "Moderate," or "Not at all." Images preceded by an M? (Movie) required participants to determine which movie genre they believed was best associated with the object or scene. There were three options for this judgment: "Action," "Horror," or "Comedy." The response options for the cued judgment always appeared below the image.

Participants were instructed to enter their responses quickly and to attempt to do so while the image was on the screen. Responses were entered with the index, middle, and ring fingers (respectively for the order of response options listed previously), and were accepted until the beginning of the next trial. Responses for one judgment were entered with the right hand and responses for the other judgment were entered with the left hand. The hand assigned to each question was counterbalanced across participants. The instructions emphasized that responding with the incorrect hand for a cued judgment counted as an incorrect response.

In addition to the critical trials, there were 24 null trials dispersed throughout each of the five scanned study sessions. The null trials displayed a white fixation cross for the duration of a normal trial $(4750 \mathrm{~ms})$ and were distributed such that 12 objects and 12 scenes were each followed by a single null trial. This was done to minimize any bias between the two image types in estimating single-trial BOLD responses. Null trials never occurred consecutively, resulting in stimulus onset asynchronies of either 4750 or $9500 \mathrm{~ms}$ for both classes of image.

Test phase. The test phase commenced outside of the scanner $\sim 15 \mathrm{~min}$ after the completion of the final study phase. Participants were shown images one at a time and were required to judge whether the image was presented in the study phase while they were in the scanner and, if so, which of the two encoding judgments they had made when they initially encountered the image. These two mnemonic decisions were combined into a single judgment with four possible options: "Old-Pleasant," "OldMovie," "Old-Don't Know," and "New." A New response was required if the image was believed to be new or if participants had a low level of confidence that the image was from the study list. An Old-Pleasant or Old-Movie response required participants to have high confidence that they studied the image and high confidence in their memory for the judgment made when the image was studied. Participants were instructed to respond Old-Don't Know if they had high confidence they studied the image but had low confidence in or were unable to remember the encoding judgment. 
Responses were entered on the keyboard by pressing the "d," " $\mathrm{f}$," “ $\mathrm{j}$," and " $k$ " keys, and these keys were labeled Old-Pleasant, Old-Movie, OldDon't Know, and New, respectively. Responses were self-paced, but participants were instructed to enter their responses quickly without sacrificing accuracy. There was a brief $500 \mathrm{~ms}$ white fixation cross between test trials. A short break was afforded to participants every 60 trials (totaling five breaks).

Practice phases. Before MRI scanning, participants practiced both the study and test phases outside of the scanner. Practice comprised three study phases and a single test phase. In the self-paced practice phase, participants were presented with the trial sequence as described above, with the exception that the image remained on the screen until a response was entered. Following a response, participants received feedback as to whether they responded to the correct judgment (i.e., whether they entered their judgment using the assigned hand for the Pleasantness or Movie judgments). The trial was repeated in the event the incorrect hand was used, and this occurred until the correct hand was used. The aim of this self-paced practice phase was to familiarize participants with responding to each type of judgment using the correct hand.

Next, participants completed a speeded practice phase. This phase was identical to the self-paced practice described above, with the exception that the image remained on the screen only for $2000 \mathrm{~ms}$. Participants were required to enter their response within this time window, otherwise they were given feedback that they did not enter a response in the allotted time. As with the self-paced practice study phase, a trial was repeated until the correct hand was used and a response was entered in the allotted time. The aim of this second practice study phase was to reinforce responding with the correct hand and to give participants experience with responding quickly. No null trials were included in the self-paced and speeded practice study phases. The final real practice study phase mirrored the procedure for the study phase proper, which is described above and included four null trials.

After the final practice study phase, participants completed the practice test phase. This mirrored the procedure for the test phase proper with the exception that no breaks were provided.

\section{Behavioral data analysis}

Trials that received no response or a response with the incorrect hand during the study phase were excluded from the analysis. Both study and test trials were binned according to the four possible test response outcomes: item hit with a correct source judgment; item hit with an incorrect source judgment; item hit accompanied by a Don't Know response for the source judgment, and item misses. Note that new items do not have a source correct judgment, thus false alarms (i.e., incorrect "old" responses to new images) were only classified as source incorrect or source Don't Know trials. The three behavioral-dependent measures analyzed included study reaction time (RT), item recognition accuracy, and source memory accuracy. Study RT was computed for each participant as the median RT for each image type and subsequent memory combination. There were three subsequent memory bins: Source Correct (SC), Source Incorrect/Don't Know (SIDK), and Item Misses (Miss). Study RT was analyzed with a 2 (Age Group: Young, Older) $\times 2$ (Image Type: Object, Scene) $\times 3$ (Subsequent Memory: SC, SIDK, Miss) mixedfactorial ANOVA.

Item recognition accuracy was computed as the difference between the hit rate to studied images (regardless of source memory accuracy) and the false alarm rate to new images. Source memory was computed using a single high-threshold model (Snodgrass and Corwin, 1988) that accounts for the "guess rate" (Mattson et al., 2014). Source accuracy was computed as follows:

$$
\text { source } p R=\frac{\text { Hit }-.5^{\star}[1-D K]}{1-.5^{\star}[1-D K]} \text {. }
$$

The Hit and DK variables in the above formula refer to the proportion of correct "old" responses (i.e., hits) accompanied by an accurate or Don't Know source memory judgment, respectively. The item and source memory scores were submitted to separate 2 (Age Group: Young, Older $) \times 2$ (Image Type: Object, Scene) mixed-factorial ANOVA.

\section{Identification of PPA and $L O C$ regions of interest}

The analyses of the fMRI data focused on two ROIs that show selective responses to scenes and objects, respectively: the PPA (Epstein and Kanwisher, 1998) and LOC (Grill-Spector et al., 2001). We identified these ROIs bilaterally using unpublished data from our laboratory obtained from a sample of 22 participants ( 14 young adults and 8 older adults) who volunteered for a previous study (Fig. 2A). Note that one young and two older participants from this unpublished study overlapped with the participants reported here. The 22 participants viewed images of faces, scenes, and articles of clothing (objects) in a mini-block design (McDuff et al., 2009; but see also Johnson et al., 2009; Wang et al., 2016) while providing a pleasantness rating for each image. PPA and LOC ROIs were obtained from a second-level general linear model (GLM) contrasting the BOLD response between scenes and objects. The two one-sided contrasts were thresholded at a familywise error (FWE)-corrected threshold of $p<0.05$, and were inclusively masked using anatomical labels from the Neuroinformatics atlas included with SPM12. The bilateral PPA ROI comprised 223 voxels ( 108 voxels in the left hemisphere) identified by the scene $>$ object contrast anatomically masked with the bilateral parahippocampal and fusiform gyri. The bilateral LOC ROI comprised 225 voxels ( 98 voxels in the left hemisphere) identified by the object $>$ scene contrast anatomically masked inferior and middle occipital gyrus ROIs defined by the Neuroinformatics atlas. The PPA and LOC ROIs used for the present study are depicted in Figure $2 A$. Additionally, Figure $2 B$ shows the statistical maps from the scene $>$ object (warm colors) and object $>$ scene (cool colors) contrasts from a second level GLM of our unpublished dataset without the anatomical inclusive mask. Figure $2 \mathrm{C}$ shows the same statistical contrast (at an identical threshold to Fig. $2 B$ ) for the 24 young and 24 older adults reported here. This is included simply for comparison purposes. Note that differences in the magnitude and extent of the contrasts in Figure 2, $B$ and $C$, are likely attributable to the larger sample size in the present study.

\section{MRI data acquisition}

MRI data were acquired with a 3 T Philips Achieva MRI scanner (Philips Medical Systems) equipped with a 32-channel receiver head coil. Functional images were acquired with a BOLD, T2*-weighted echoplanar imaging $(\mathrm{EPI})$ sequence $\left(\mathrm{SENSE}\right.$ factor $=1.5$; flip angle $=70^{\circ} ; 80 \times 80$ matrix; FOV $=240 \times 240 \mathrm{~mm} ; \mathrm{TR}=2000 \mathrm{~ms} ; \mathrm{TE}=30 \mathrm{~ms} ; 34$ ascending slices; slice thickness $=3 \mathrm{~mm}$; slice gap $=1 \mathrm{~mm}$ ) and were oriented parallel to the anterior commissure-posterior commissure axis. Five "dummy" scans were acquired at the start of each EPI session and discarded to allow for equilibration of tissue magnetization. A total of 180 functional volumes were acquired during each study session, for a total of 900 brain volumes. T1-weighted images (MPRAGE sequence, $240 \times 240$ matrix, $1 \mathrm{~mm}$ isotropic voxels) were acquired for anatomical reference following before the first study session.

\section{Formation of study-specific MNI templates}

A sample-specific EPI template was created using the mean EPI image from all participants included in the analysis following previously published procedures (de Chastelaine et al., 2011, 2016). Each participant's mean EPI image was first normalized to the standard EPI template in SPM12, and the spatially normalized images were then averaged within age group to create a young and older adult EPI template. The final template was created by averaging the two age-specific templates.

\section{fMRI preprocessing}

The functional data were preprocessed with Statistical Parametric Mapping (SPM12, Wellcome Department of Cognitive Neurology, London, UK) implemented in Matlab 2017b (MathWorks). The functional data were reoriented, subjected to a two-pass realignment procedure whereby images were first realigned to the first image of a session and then realigned to a mean EPI image, and corrected for slice acquisition time differences using sinc interpolation with reference to the middle slice. Finally, images were spatially normalized to a study-specific EPI template (see Creation of study-specific MNI templates), and smoothed with an 8 $\mathrm{mm}$ full-width at half-maximum kernel.

The data from the five study sessions were concatenated and subjected to a least-squares-all GLM to estimate the BOLD response to individual 

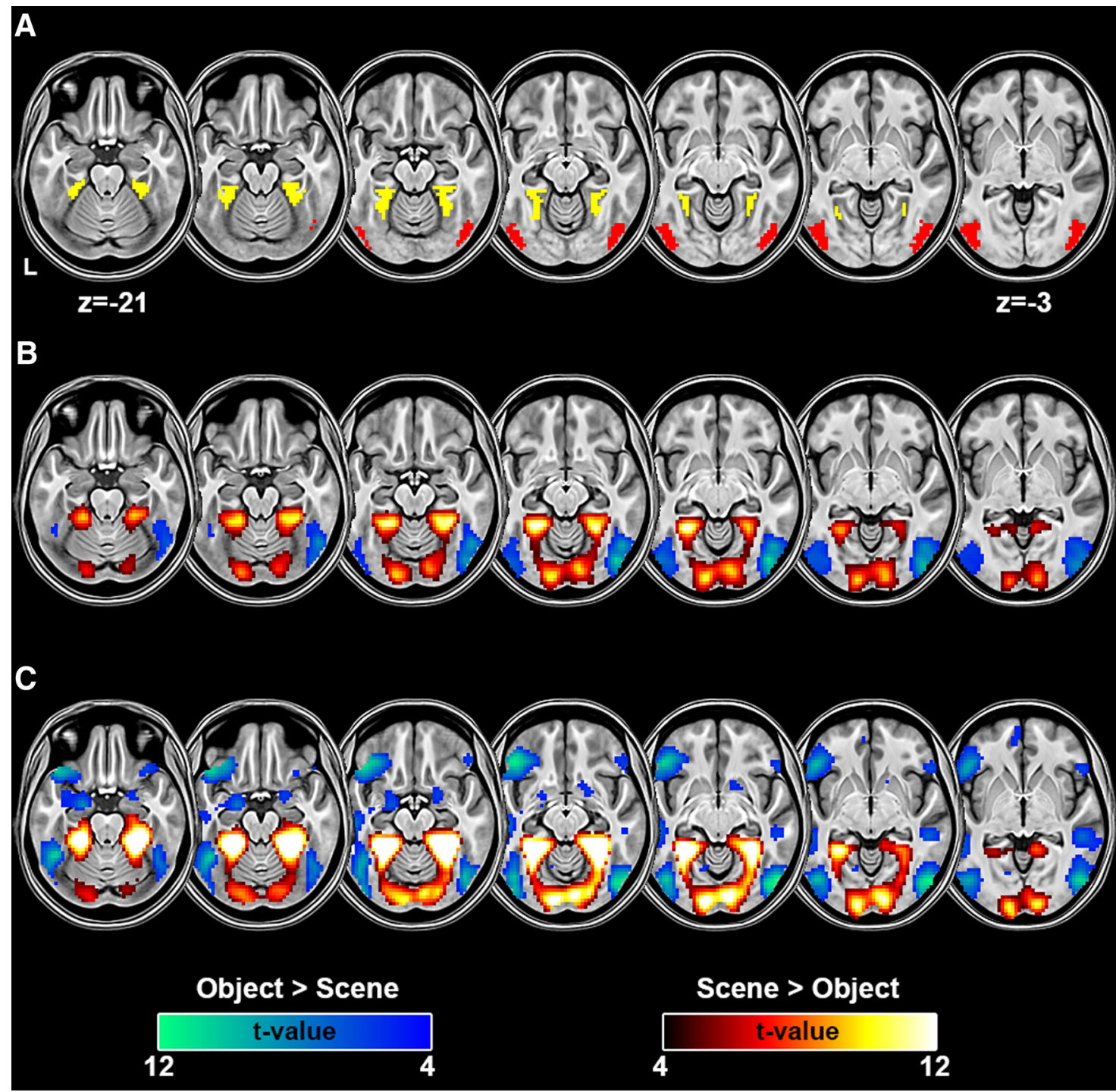

Figure 2. A, Voxels comprising the regions-of-interest (ROIs) in the PPA (yellow voxels) and LOC (red voxels) derived from an unpublished dataset. Note that the ROIs were anatomically masked using the Neuroinformatics atlas included in SPM12. The anatomical labels for this mask included bilateral parahippocampal, fusiform, middle occipital, and inferior occipital gyri. $\boldsymbol{B}$, Statistical parameteric maps (SPMs) from the unpublished experiment showing the one-tailed contrasts of Scene $>0$ 0bjects and 0bjects $>$ Scenes. C, SPMs for the Scene $>0$ 0bjects and Objects $>$ Scene contrast in the 24 young and 24 older adults in the present data (collapsed across age group). The SPMs are thresholded at FWE of $p<0.05$.

trials (Rissman et al., 2004; Mumford et al., 2014). Events were modeled as a 2-s-duration boxcar convolved with a canonical HRF. Covariates of no interest in this first-level model included the six rigid body motion parameters estimated from the realignment procedure and four sessionspecific means (for sessions 2-5).

\section{Differentiation index analysis}

We computed a differentiation index for the PPA and LOC ROIs (see Identifying PPA and LOC regions of interest). For each trial, we extracted the average BOLD amplitude separately for each ROI (collapsed across hemisphere). These individual trial values were used to compute separate differentiation indices for each bilateral ROI using a formula similar to that used by Voss et al. (2008). The index is essentially a discrimination metric similar to the $d^{\prime}$ signal detection measure (Macmillan and Creelman, 2005) and was computed using the following formula:

$$
\text { Differentiation Index }=\frac{\mu_{\text {Pref }}-\mu_{\text {Non-Pref }}}{\sqrt{\frac{\sigma_{\text {Pref }}^{2}+\sigma_{\text {Non-Pref }}^{2}}{2}}} .
$$

In the above equation, $\mu_{\text {Pref }}$ and $\sigma_{\text {Pref }}^{2}$ refer to the across-trial mean and variance, respectively, of the BOLD response to the preferred image type of an ROI. The $\mu_{\text {Non-Pref }}$ and $\sigma_{\text {Non-Pref }}^{2}$ terms refer to the across-trial mean and variance, respectively, of the nonpreferred image type. For the PPA, scenes were designated as the preferred image type and objects as the nonpreferred image type, and this designation was reversed for the LOC.

Positive values of the differentiation index reflect higher "selectivity" of responding to the preferred image type of an ROI. We note two aspects of this index that bear mention. First, and importantly, the differentiation index is insensitive to across-participant variability in the HRF and, therefore, is unbiased by putative systematic age differences in such factors as cerebral vascular reactivity (see, for example, Liu et al., 2013). Second, the index is a metric of category selectivity and does not measure selectivity at the "item level" (Xue et al., 2010; for potential approaches to item level distinctiveness, see Goh et al., 2010; St-Laurent et al., 2014). The differentiation index data were subjected to a 2 (Age Group) $\times 2$ (ROI: PPA, LOC) mixed factorial ANOVA.

An additional ANOVA of the differentiation index data was conducted in which subsequent memory bin (SC, SIDK, Miss) was included as a factor. This ANOVA produced results identical to the $2 \times 2$ ANOVA described above, with no effects involving subsequent memory. Thus, for the sake of simplicity, we focus below on the differentiation index computed across all trials regardless of subsequent memory judgment. 
The differentiation index is ambiguous with respect to whether a group difference, if any, is driven by reduced BOLD signal for the preferred image type (i.e., neural attenuation), an increase in BOLD signal for the nonpreferred image type (i.e., neural broadening), or by both effects (Park et al., 2012). To investigate this issue, we also examined the mean BOLD responses elicited by each image type within the two ROIs using a 2 (Age Group) $\times 2($ ROI $) \times 2$ (Image Type: Object, Scene) mixed factorial ANOVA.

A primary goal of the present study was to examine whether neural differentiation during encoding is predictive of subsequent memory performance. We addressed this issue by computing across-participant correlations between the PPA and LOC differentiation indices and performance on the experimental memory task (i.e., item recognition and source memory scores). Additionally, we computed partial correlations between these indices after controlling for several relevant variables, including age group, item, or source memory performance (when source and item memory were in the zero-order correlation, respectively) and visual acuity.

For clarity, we focus here on the partial correlations. Results from multiple regression analyses led to conclusions identical to those derived from the partial correlation analyses reported below. Of importance, the inclusion of an interaction term between age and the neural differentiation indices in the regression models did not significantly increase the amount of explained variance compared with models with only age group and differentiation indices as predictors $\left(F_{(1,44)}<2.83, p \geq\right.$ $0.100)$, nor did the regression coefficients for the interaction terms approach significance. Thus, we found no support that any of the reported correlations between differentiation indices and memory performance were moderated by age group. Moreover, in the analyses reported below, partial correlations were computed after averaging the memory measures across image type, as there was no indication that the effects of interest were moderated by this variable. Specifically, in a multilevel regression conducted with the lmerTest package in $R$ (Kuznetsova et al., 2015), no interaction term that involved that variable of image type approached significance (all regression coefficients $p$ values $\geq 0.136$. The full results from these multiple and multilevel regression analyses are available from J.D.K. upon request.

In addition to the correlation analyses involving memory performance, we also examined the relationship between the differentiation indices and the extracted factor scores for the neuropsychological test battery (see Analysis of neuropsychological data), again with partial correlations. Importantly, as with the two memory measures, multiple regression provided no evidence that the relationship between any of the factor scores and the differentiation indices were moderated by age group $\left(F_{(1,44)}<1.66, p \geq 0.204\right)$. A multilevel regression model including a factor for the four RC scores led to identical conclusions to those derived from the partial correlations reported below. These regression analyses also are available from J.D.K. upon request.

\section{Pattern similarity analysis}

To complement the analyses of the univariate differentiation index described above, we also conducted a pattern similarity analysis (Kriegeskorte et al., 2008). All similarity computations were conducted on singletrial $\beta$ weights (see above) and were based on Fisher $z$-transformed Pearson's correlation coefficients. A within-minus-between (henceforth within-between) similarity metric was computed separately for each ROI with the preferred and nonpreferred image category serving as the within and between measure, respectively. For the PPA, the within-category measure was the average across-voxel similarity between a given scene trial with all other scene trials. The between-category similarity measure was the average correlation between a given scene trial and all object trials. For each scene trial in the PPA, the within-between measure was computed as the difference between the above-described within and between similarity metrics. A summary measure for a participant was computed by averaging all of the trialwise within-between measures. The same approach was used to compute the within-between similarity metric for the LOC, except that object trials were used for the within-category measures, and scene trials provided the between-category measures. We refer to the metric as the "similarity index." Analogous to the differenti-
Table 3. Mean (and SEs) for the median RT to judgments made during the study phase

\begin{tabular}{llllll}
\hline \multirow{2}{*}{ Subsequent memory } & \multicolumn{2}{l}{ Young adults (ms) } & & \multicolumn{2}{l}{ Older adults (ms) } \\
\cline { 2 - 3 } & Object & Scene & & Object & Scene \\
\hline Source correct & $1356(63)$ & $1314(69)$ & & $1293(31)$ & $1320(33)$ \\
Source Incorrect/Don't Know & $1438(63)$ & $1424(73)$ & & $1365(45)$ & $1368(47)$ \\
Item miss & $1445(58)$ & $1444(71)$ & & $1343(50)$ & $1383(44)$ \\
\hline
\end{tabular}

ation index described above, the similarity index is a measure of similarity at the category and not the item level. The similarity indices were subjected to a 2 (Age Group) $\times 2$ (ROI: PPA, LOC) mixed factorial ANOVA.

As for the univariate differentiation index described above, ANOVA of the similarity metrics that included a subsequent memory factor (SC, SIDK, and Miss) revealed no effects involving subsequent memory. Therefore, we report the similarity findings collapsed across subsequent memory judgment. Further echoing the analyses of the differentiation index, we examined the associations among the pattern similarity index and memory and neuropsychological test performance, and report the findings in terms of partial correlations. Analysis using multiple regression led to identical conclusions; crucially, there was no indication that adding a term for the interaction between age group and the similarity index improved model fit beyond that obtained with models without this term $\left(F_{(1,44)}<1.35, p \geq 0.144\right)$, nor did the regression coefficients for any of the interaction terms approach significance. Thus, we found no evidence that the correlations reported between the pattern similarity index and cognitive performance were moderated by age group.

\section{Results}

\section{Neuropsychological test performance}

The results from the different measures of the neuropsychological test battery are reported in Table 1 . The pattern of age differences is essentially identical to that in our prior report (Koen et al., 2018), which is not surprising given the high degree of overlap between the samples (see Participants in Materials and Methods). There were significant effects of age, with older adults performing worse on tests assessing declarative memory, reasoning ability, category fluency, and processing speed. However, older adults were equally proficient at word reading and verbal fluency relative to young adults. Finally, as expected (Baltes and Lindenberger, 1997), older participants had lower visual acuity than younger adults.

The bottom portion of Table 1 shows extracted factor scores derived from the test (Table 2, rotated PCA loadings; Neuropsychogical test analysis). Not surprisingly, and consistent with the analysis of the individual tests, there were age differences in the speed (RC1) and memory (RC2) factors. No age differences were observed for the factors corresponding to crystallized intelligence (RC3) and fluency (RC4).

\section{Study reaction time}

Table 3 shows the descriptive statistics of the median RTs for the study judgments. A 2 (Age Group) $\times 2$ (Image Type) $\times 3$ (Subsequent Memory) mixed ANOVA revealed a main effect of subsequent memory $\left(F_{(1.96,90.31)}=24.43, \mathrm{MS}_{\mathrm{e}}=8705, p<10^{-8}\right.$, partial- $\eta^{2}=0.35$ ) that was driven by faster RTs for subsequent source correct trials (mean $=1321$ ) relative to both source incorrect $\left(\right.$ mean $\left.=1399 ; t_{(92)}=5.86, \mathrm{SE}=13.34, p<10^{-4}\right)$ and item miss trials $\left(\right.$ mean $\left.=1404 ; t_{(92)}=6.23, \mathrm{SE}=13.34, p<10^{-4}\right)$. There was no significant difference between study RTs associated with subsequent incorrect source memory and item misses $\left(t_{(92)}=0.37, \mathrm{SE}=13.34, p=0.712\right)$. Nor were there any significant effects involving age group (all $p$ values involving Age Group >0.133). 
Table 4. Means (with SEs) for the proportion of trials in each cell formed by age group, image type, and item type (old vs new) for the four possible memory response bins

\begin{tabular}{|c|c|c|c|c|c|c|c|c|}
\hline \multirow{3}{*}{$\begin{array}{l}\text { Test } \\
\text { response }\end{array}$} & \multicolumn{4}{|c|}{ Young adults } & \multicolumn{4}{|l|}{ Older adults } \\
\hline & \multicolumn{2}{|l|}{ Objects } & \multicolumn{2}{|l|}{ Scenes } & \multicolumn{2}{|l|}{ Objects } & \multicolumn{2}{|l|}{ Scenes } \\
\hline & Old & New & Old & New & Old & New & Old & New \\
\hline Old + SC & $0.58(0.05)$ & & $0.32(0.03)$ & & $0.56(0.04)$ & & $0.34(0.03)$ & \\
\hline Old + SI & $0.04(0.01)$ & $0.01(0.01)$ & $0.05(0.01)$ & $0.03(0.01)$ & $0.13(0.02)$ & $0.08(0.02)$ & $0.12(0.02)$ & $0.14(0.03)$ \\
\hline Old + DK & $0.21(0.03)$ & $0.04(0.02)$ & $0.29(0.02)$ & $0.11(0.02)$ & $0.14(0.03)$ & $0.03(0.04)$ & $0.24(0.03)$ & $0.15(0.03)$ \\
\hline New & $0.17(0.03)$ & $0.95(0.02)$ & $0.33(0.04)$ & $0.86(0.03)$ & $0.17(0.02)$ & $0.89(0.02)$ & $0.30(0.03)$ & $0.72(0.04)$ \\
\hline
\end{tabular}

It is impossible to have a source correct response for new trials. Thus, incorrect old responses to new items are classified as a source incorrect (SI) trial if participants selected one of the two encoding tasks or as a source don't know (DK) trial if participants selected the Don't Know response option.

Table 5. Means (with SEs) estimates of item and source memory discrimination

\begin{tabular}{llllll}
\hline & \multicolumn{2}{l}{ Item recognition } & & \multicolumn{2}{l}{ Source memory } \\
\cline { 2 - 3 } Age group & Object & Scene & & Object & Scene \\
\hline Young adults & $0.78(0.04)$ & $0.52(0.04)$ & & $0.51(0.05)$ & $0.27(0.03)$ \\
Older adults & $0.72(0.03)$ & $0.42(0.03)$ & & $0.44(0.04)$ & $0.25(0.03)$ \\
\hline
\end{tabular}

Item recognition reflects the difference between the hit and false alarm rate regardless of source memory accuracy. Source memory was computed with the source pR formula (see Behavioral data analysis) only for studied images attracting an accurate old response.

\section{Memory performance}

Table 4 shows the mean proportion of responses given to test items as a function of age group, image type, and study status (old or new), while Table 5 reports the item and source memory scores for objects and scenes in young and older adults. A 2 (Age Group) $\times 2$ (Image Type) mixed factorial ANOVA on the item recognition measure revealed a significant main effect of image type $\left(F_{(1,46)}=187.97, \mathrm{MS}_{\mathrm{e}}=0.01, p<10^{-15}\right.$, partial- $\left.\eta^{2}=0.80\right)$, reflecting better item recognition for objects than scenes. Although older adults (mean $=0.57, \mathrm{SE}=0.03$ ) demonstrated numerically lower item recognition scores than young adults (mean $=0.65, \mathrm{SE}=0.03)$, the main effect of age group was not significant according to our a priori statistical threshold $\left(F_{(1,46)}=\right.$ $3.89, \mathrm{MS}_{\mathrm{e}}=0.04, p=0.055$, partial- $\left.\eta^{2}=0.08\right)$. The interaction between age and image type was not significant $\left(F_{(1,46)}=1.04\right.$, $\mathrm{MS}_{\mathrm{e}}=0.01, p=0.312$, partial $-\eta^{2}=0.02$ ).

An analogous $2 \times 2$ mixed factorial ANOVA on the source memory measure also produced a significant main effect of image type $\left(F_{(1,46)}=105.05, \mathrm{MS}_{\mathrm{e}}=0.01, p<10^{-12}\right.$, partial- $\left.\eta^{2}=0.70\right)$, which was driven by better source memory for objects than for scenes (Table 5). There was no significant difference in source memory accuracy between young and older adults $\left(F_{(1,46)}=0.81\right.$, $\mathrm{MS}_{\mathrm{e}}=0.06, p=0.372$, partial $\left.-\eta^{2}=0.02\right)$, nor was there a significant interaction between age and image type $\left(F_{(1,46)}=0.97\right.$, $\mathrm{MS}_{\mathrm{e}}=0.01, p=0.329$, partial $\left.-\eta^{2}=0.02\right)$.

\section{Differentiation index}

The results from the fMRI differentiation index are presented in Figure $3 A$. A 2 (Age Group) $\times 2$ (ROI) mixed factorial ANOVA on these data produced a significant interaction $\left(F_{(1,46)}=20.31\right.$, $\mathrm{MS}_{\mathrm{e}}=0.06, p<10^{-4}$, partial- $\left.\eta^{2}=0.31\right)$. The interaction was driven by significantly lower differentiation indices from the PPA in older relative to younger adults $\left(t_{(91.71)}=5.76, p<10^{-4}\right)$. No age differences were observed in the LOC differentiation index $\left(t_{(91.71)}=0.60, p=0.551\right)$.

To investigate whether the age-related reduction in the PPA differentiation index resulted from reduced BOLD signal for the preferred stimulus type of the region (i.e., neural attenuation), increased BOLD signal for an ROI nonpreferred stimulus type (i.e., neural broadening), or a mixture of the two, we conducted a 2 (Age Group) $\times 2(\mathrm{ROI}) \times 2$ (Image Type) mixed factorial ANOVA on the mean BOLD responses (Fig. 3B). The ANOVA produced a significant three-way interaction $\left(F_{(1,46)}=37.76\right.$, $\mathrm{MS}_{\mathrm{e}}=0.45, p<10^{-6}$, partial- $\left.\eta^{2}=0.31\right)$. Post hoc tests demonstrated that the mean BOLD response in the PPA was significantly lower for older relative to young adults when viewing scenes (i.e., the preferred stimulus type; $\left.t_{(89.34)}=4.51, p<10^{-4}\right)$. No age differences were present in the PPA during object trials (i.e., the nonpreferred stimulus type; $t_{(89.34)}=0.62, p=0.535$ ), nor were age differences present in the LOC for either objects $\left(_{(89.34)}=\right.$ $1.72, p=0.088)$ or scenes $\left(t_{(89.34)}=1.14, p=0.257\right)$.

\section{Relationship with memory performance}

The zero-order correlations between item and source memory (averaged across image type), the PPA and LOC differentiation indices, visual acuity, and age group are shown in Table 6. Our primary hypothesis concerned the relationship between memory performance and the differentiation indices. As can be seen in Table 6, the differentiation index from the PPA, but not the LOC, was correlated with both item and source memory. Given the lack of significant correlations with the LOC, the results reported below focus solely on the PPA.

First, we focus on the correlation between item recognition and the PPA differentiation index. Importantly, this correlation remained significant after partialling out age group $\left(r_{\text {partial }}(45)=\right.$ $0.48, p<0.001$; Fig. $4 A$ ). This result, in conjunction with the absence of a moderating effect of age (see Differentiation index analysis in Materials and Methods), suggests that the correlation between item recognition and the PPA differentiation index is age invariant. It is possible that the correlation between item recognition and PPA differentiation index is due to shared variance with source memory. Critically, the partial correlation between item recognition and PPA differentiation index controlling for both age group and source memory remained significant $\left(r_{\text {partial }}(44)=0.33, p=0.023\right.$; Fig. $\left.4 B\right)$, suggesting that source memory does not account for the relationship between the differentiation index and item recognition. We also examined whether the correlation between item recognition and the PPA differentiation index was due to shared variance with visual acuity. Echoing the above analysis, the partial correlation between item recognition and the PPA differentiation index after controlling for both age group and visual acuity remained significant $\left(r_{\text {partial }}(44)=0.46, p=0.001\right)$.

A set of partial correlations similar to that described above was computed for the relationship between source memory performance and the PPA differentiation index. As with item recognition, the partial correlation between source memory and the PPA differentiation index was significant after controlling for age group $\left(r_{\text {partial }}(45)=0.36, p=0.011\right.$; Fig. $\left.4 C\right)$ and for both age group and visual acuity $\left(r_{\text {partial }}(44)=0.35 p=0.016\right)$. However, the correlation was no longer significant and, indeed, was near zero after controlling for age group and item recognition performance $\left(r_{\text {partial }}(44)=0.04, p=0.779\right)$. 

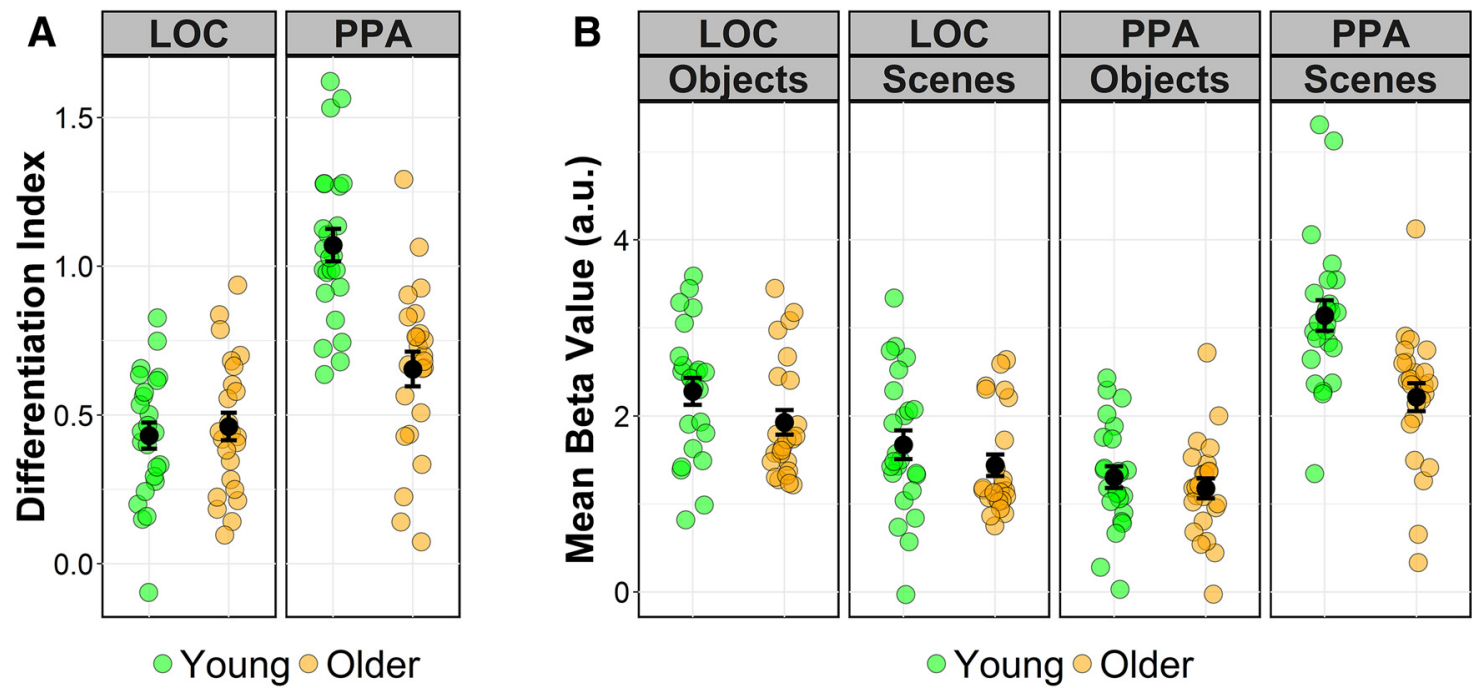

Figure 3. A, Plot of the differentiation index computed from the LOC and PPA for young and older adults. $B$, Plot of the across-trial mean $\beta$-values for each image type and region of interest. Each green and orange circle represents an individual participant's data, and the black circle represents the group mean, with error bars denoting \pm 1 SEM.

Table 6. Zero-order correlations among memory performance, differentiation index, similarity index, visual acuity, and age

$$
\text { (1) (2) }
$$

(1) Item recognition

(2) Source memory

(3) PPA differentiation index

$0.71(<0.001)$

(4) LOC differentiation index

$0.53(<0.001)$

$0.09(0.559)$

(5) PPA similarity index

(6) LOC similarity index

$0.50(<0.001)$

$0.37(0.010)$

$0.03(0.837)$

$0.25(0.083)$

$0.32(0.026)$

$0.15(0.298)$

(7) Visual acuity

$-0.35(0.016)$

(8) Age group

$-0.28(0.055)$

$-0.16(0.268)$

$-0.13(0.372)$

$\begin{aligned} & 0.00(0.988) \\ & 0.78(<0.001) \\ & 0.31(0.030) \\ &-0.48(0.001) \\ &-0.61(<0.001)\end{aligned}$

$-0.08(0.580)$
$0.71(<0.001)$
$0.04(0.799)$

$0.04(0.799) \quad-0.45(0.001)$

$0.07(0.632)$

Correlations were computed using Pearson's $r$. Item and source memory correlations are based on the measures after averaging across image type.

In summary, we observed a significant correlation between item recognition and PPA differentiation index that was invariant across age group, source memory performance, and visual acuity. Although the PPA differentiation index was significantly correlated with source memory, this association appeared to result from shared variance with item recognition.

Relationship with neuropsychological test performance

Table 7 shows the zero-order correlation among the four neuropsychological factors (RCs), visual acuity, differentiation indices, and age group. The PPA, but not the LOC, differentiation index correlated significantly with the RCs corresponding to speed, memory, and fluency. To examine whether these correlations were independent of age, we computed partial correlations between the PPA differentiation index and the four RCs controlling for age. [It is important to reiterate that there was no indication of an interaction between age group and PPA differentiation index for any of the four RCs (see Analysis of relationships between neural differentiation and cognition).] The partial correlation for the speed $\left(r_{\text {partial }}(45)=-0.09, p=\right.$ $0.561)$, memory $\left(r_{\text {partial }}(45)=-0.05, p=0.759\right)$, and crystallized intelligence $\left(r_{\text {partial }}(45)=0.11, p=0.468\right)$ factors all failed to reach our significance threshold. Thus, the zeroorder correlations between neural differentiation with the speed and memory factors reflect variance that is also shared with age group. In contrast, the partial correlation between the PPA differentiation index and the fluency factor remained significant $\left(r_{\text {partial }}(45)=0.35, p=0.017\right.$; Fig. 5), suggesting that neural differentiation and fluency have an age-invariant relationship. This correlation remained significant after controlling for visual acuity in addition to age $\left(r_{\text {partial }}(44)=0.36\right.$, $p=0.014)$.

\section{Pattern similarity index}

A 2 (Age Group) $\times 2$ (ROI) mixed ANOVA produced a significant interaction $\left(F_{(1,46)}=25.11, \mathrm{MS}_{\mathrm{e}}=0.003, p<10^{-5}\right.$, partial- $\eta^{2}=0.35$; Fig. $6 \mathrm{~A}$ ). The interaction was driven by older adults showing lower similarity indices relative to younger adults in the PPA $\left(t_{(91.97)}=8.55, p<10^{-12}\right)$, but not in the LOC $\left(t_{(91.97)}=1.40, p=0.164\right)$. These findings mirror those observed for the univariate differentiation index and offer strong convergent evidence for age-related neural dedifferentiation in the PPA.

\section{Relationship with memory performance}

The zero-order correlations between item and source memory (averaged across image type) and the pattern similarity indices are shown in Table 6. As with the differentiation index, there were no significant correlations involving the LOC similarity index. Thus, we focus the partial correlation analysis on the index from the PPA. The correlation between item recognition and the PPA similarity index remained significant after partialling out age group $\left(r_{\text {partial }}(45)=0.45, p=0.002\right.$; Fig. $\left.6 B\right)$. This result, in conjunction with the absence of a moderating effect of age (see Pattern similarity analysis in Materials and Methods), suggests that the correlation between item recognition and the similarity index in the PPA is age invariant. Moreover, the correlation remained significant after partialling out both age group and source memory performance $\left(r_{\text {partial }}(44)=0.33, p=0.025\right)$, and age 
A
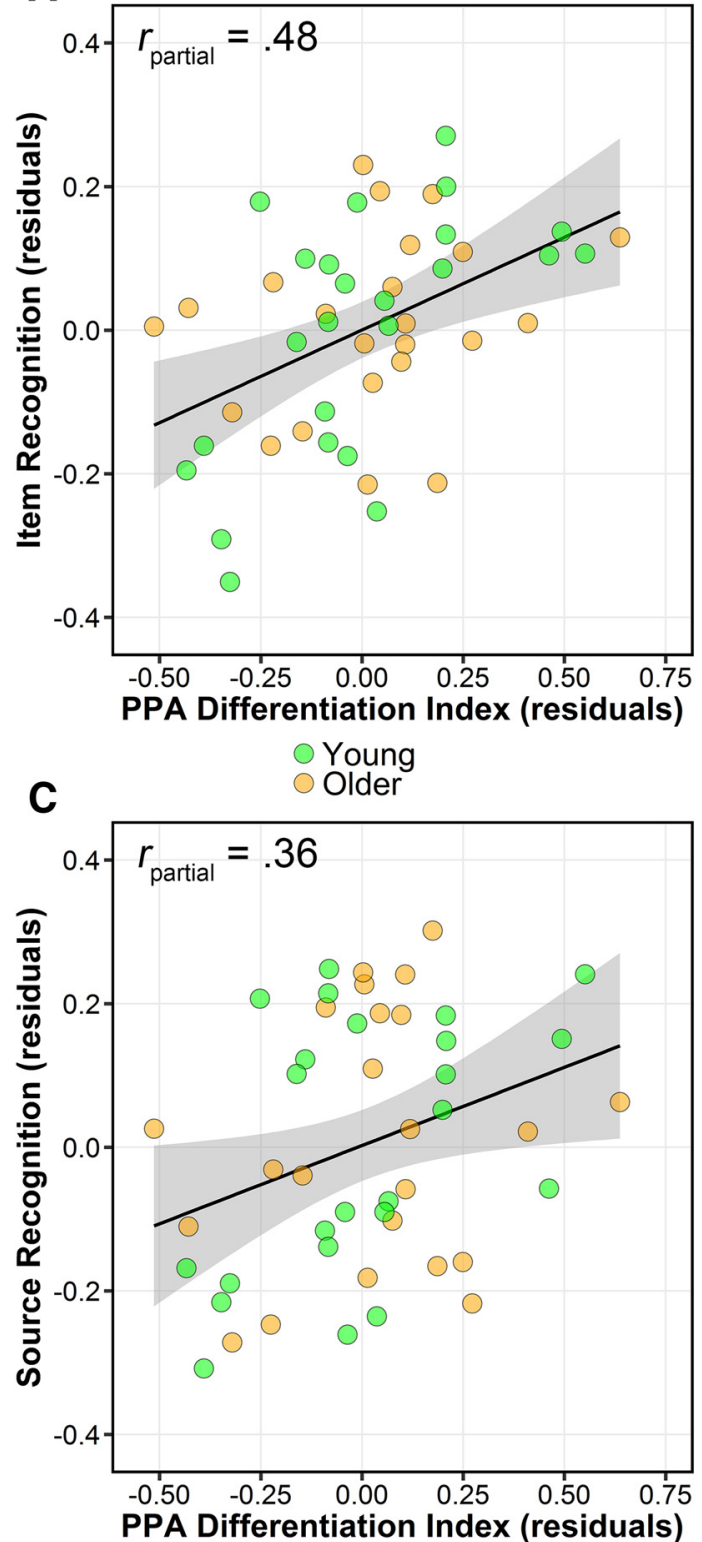

B
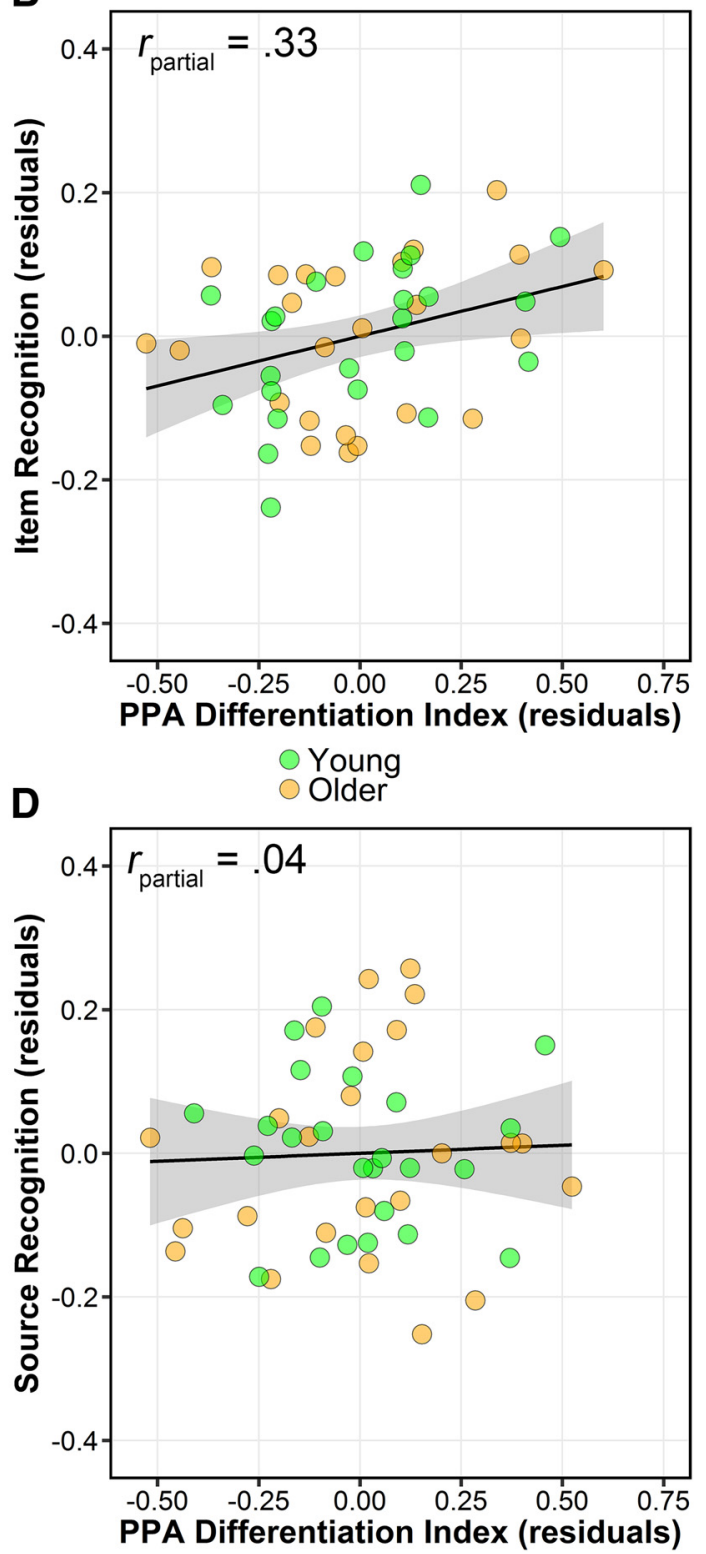

Figure 4. $\quad A-D$, Scatter plots showing the partial correlation between the PPA differentiation index and item recognition $(A, B)$ and source memory $(C, D)$. The partial plots control for age group $(\boldsymbol{A}, \boldsymbol{C})$, age group and source memory $(\boldsymbol{B})$, and age group and item recognition $(\boldsymbol{D})$.

Table 7.Zero-order correlations between factor scores from the neuropsychological test performance, differentiation index, similarity index, visual acuity, and age

\begin{tabular}{lrrrr}
\hline & \multicolumn{1}{l}{ (1) } & (2) & \multicolumn{1}{l}{ (3) } \\
\hline (1) Speed (RC1) & & & & \\
(2) Memory (RC2) & $-0.46(0.001)$ & & & \\
(3) Crystallized IQ (RC3) & $0.16(0.279)$ & $0.10(0.498)$ & & \\
(4) Fluency (RC4) & $-0.27(0.061)$ & $-0.27(0.061)$ & $0.16(0.287)$ & \\
Correlations with & & & & \\
$\quad$ PPA differentiation index & $-0.40(0.004)$ & $0.31(0.030)$ & $0.06(0.700)$ & $0.37(0.009)$ \\
LOC differentiation index & $-0.02(0.908)$ & $0.00(0.989)$ & $-0.08(0.612)$ & $-0.08(0.584)$ \\
PPA similarity index & $-0.48(0.001)$ & $0.34(0.019)$ & $0.09(0.560)$ & $0.30(0.04)$ \\
LOC similarity index & $-0.23(0.114)$ & $0.14(0.345)$ & $-0.05(0.739)$ & $0.20(0.182)$ \\
Visual acuity & $0.40(0.005)$ & $-0.41(0.003)$ & $0.05(0.738)$ & $-0.06(0.677)$ \\
Age group & $0.57(<0.001)$ & $-0.56(<0.001)$ & $0.05(0.751)$ & $-0.17(0.257)$ \\
\hline
\end{tabular}

The correlations among visual acuity, PPA differentiation/similarity index, LOC differentiation/similarity index, and age group are identical to those in reported in Table 6. group and visual acuity $\left(r_{\text {partial }}(44)=0.46, p=0.002\right)$. These latter two results suggest that the correlation between item recognition and the PPA similarity index was not driven by variance shared with source memory or visual acuity, respectively.

The correlation between source memory and the PPA similarity index was also age invariant, $r_{\text {partial }}(45)=0.32, p=0.026$. Although this correlation remained significant when partialling out age group and visual acuity $\left(r_{\text {partial }}(44)=0.32, p=0.028\right)$, adding item recognition as a covariate along with age group rendered the correlation nonsignificant $\left(r_{\text {partial }}(45)=0.01, p=\right.$ $0.946)$. Thus, the results using the pattern similarity index parallel those for the differentiation index in that the metric of neural differentiation predicted item, but not source, memory in an age-invariant manner.

Relationship with neuropsychological test performance

Table 7 shows the zero-order correlation among the four neuropsychological factors (RCs) and the PPA and LOC similarity in- 


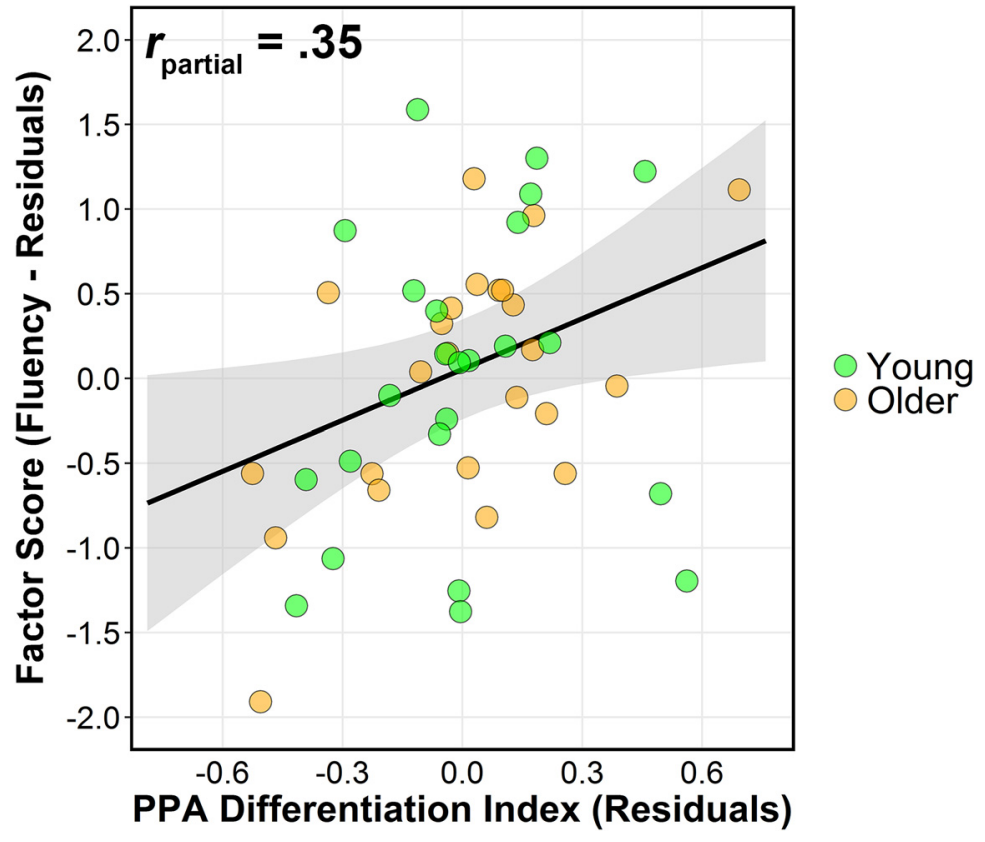

Figure 5. Scatter plots showing the partial correlation between the PPA differentiation index and the factor score for fluency (RC4) controlling for age.

dices. Again, we focus on the PPA as none of the zero-order correlations for the LOC similarity index reached our significance threshold. The partial correlation for the speed $\left(r_{\text {partial }}(45)=\right.$ $-0.13, p=0.367)$, memory $\left(r_{\text {partial }}(45)=-0.10, p=0.512\right)$, crystallized intelligence $\left(r_{\text {partial }}(45)=0.17, p=0.258\right)$, and fluency $\left(r_{\text {partial }}(45)=0.26, p=0.080\right)$ factors all failed to reach our significance threshold after controlling for age group. The lack of a significant partial correlation between the PPA similarity index (controlling for age group) and the fluency factor stands in contrast to findings for the differentiation index reported above. It is noteworthy, however, that the correlation was sizeable and in the same direction as that for the differentiation index.

\section{Discussion}

We describe three main findings. First, we replicated prior findings (Park et al., 2004, 2012; Voss et al., 2008) by showing agerelated reductions in two measures of category-level neural differentiation (henceforth, collectively termed neural differentiation indices). These age differences were observed only in the PPA, and not in the LOC. Second, we found an age-invariant relationship between neural differentiation in the PPA and item recognition memory. Last, a similarly age-invariant relationship was evident between a "fluency" factor derived from neuropsychological test scores and neural differentiation (albeit, reaching significance only for the differentiation index). Together, the findings suggest that neural differentiation in the PPA is associated with two independent sources of variance: age and cognitive performance.

\footnotetext{
Absence of age differences in item and source memory

No age differences were observed in study RT, item recognition, or source memory. While age differences in RT might be expected, null age effects on study RT have been reported previously in tasks very similar to the present one (de Chastelaine et al., 2011, 2016; Mattson et al., 2014; Wang et al., 2016). The lack of an age difference in source memory is more surprising given well documented age-related deficits in recollection (Koen and
}

Yonelinas, 2014; Schoemaker et al., 2014) and source memory (Spencer and Raz, 1995; Old and Naveh-Benjamin, 2008). This null finding might reflect our use of an atypical older sample. This is a perennial concern in neuroimaging studies of aging (Rugg, 2017), but is mitigated here by the "standard" pattern of impaired and preserved neuropsychological test performance demonstrated by our older participants (Park et al., 2002; Drag and Bieliauskas, 2010). A second possibility is that age differences in source memory were masked by an especially conservative response bias in young adults. This could have resulted from our instruction to report source memory decisions only when confidence was high. In complying, young adults might have withheld what would have been accurate decisions because their response criteria were set above the threshold necessary for accurate responding, lowering their source accuracy and attenuating potential age differences. Last, the encoding tasks might have disproportionately benefited memory encoding in older adults, an effect that has sometimes been reported to eliminate age differences in recollection (Luo et al., 2007). Although the last two accounts are not mutually exclusive, the latter account also accommodates the null age effects on item memory.

\section{The age component of neural differentiation}

Our findings demonstrate that age-related neural dedifferentiation in the PPA is driven by diminished BOLD responses to scenes in older adults ("neural attenuation"; Park et al., 2012). Counter to prior findings (Park et al., 2004; for related findings, see Berron et al., 2018), we did not observe significant age differences in neural differentiation in the LOC, a region selectively responsive to objects from a wide variety of categories (GrillSpector et al., 2001). This null finding for the LOC is not unprecedented: Chee et al. (2006) also reported null age differences in the LOC for objects (relative to scenes); relatedly, Voss et al. (2008) reported null effects of age on neural selectivity for familiar words and colors.

Our results add to the evidence for age-related neural dedifferentiation, but do little to elucidate its functional significance. Any account must, however, accommodate the present and prior findings (see above) that age-related dedifferentiation is evident only for some stimulus classes. One possibility (raised by a reviewer) is that the present findings have their origin not in the way different neural regions represent visual categories as a function of age, but in age-related differences in eye movements. By this argument, the results for the PPA reflect the adoption by older and younger adults of different scanning strategies when confronted with scenes (Açłk et al., 2010). This account cannot be definitively ruled out in the absence of eye-movement data (which, to our knowledge, have yet to be reported in any relevant study). We note, however, that it cannot be a general explanation of age-related neural differentiation, which has been reported not only for visual stimuli, but for auditory stimuli and motoric activity also (Carp et al., 2011a; Grady et al., 2011). 

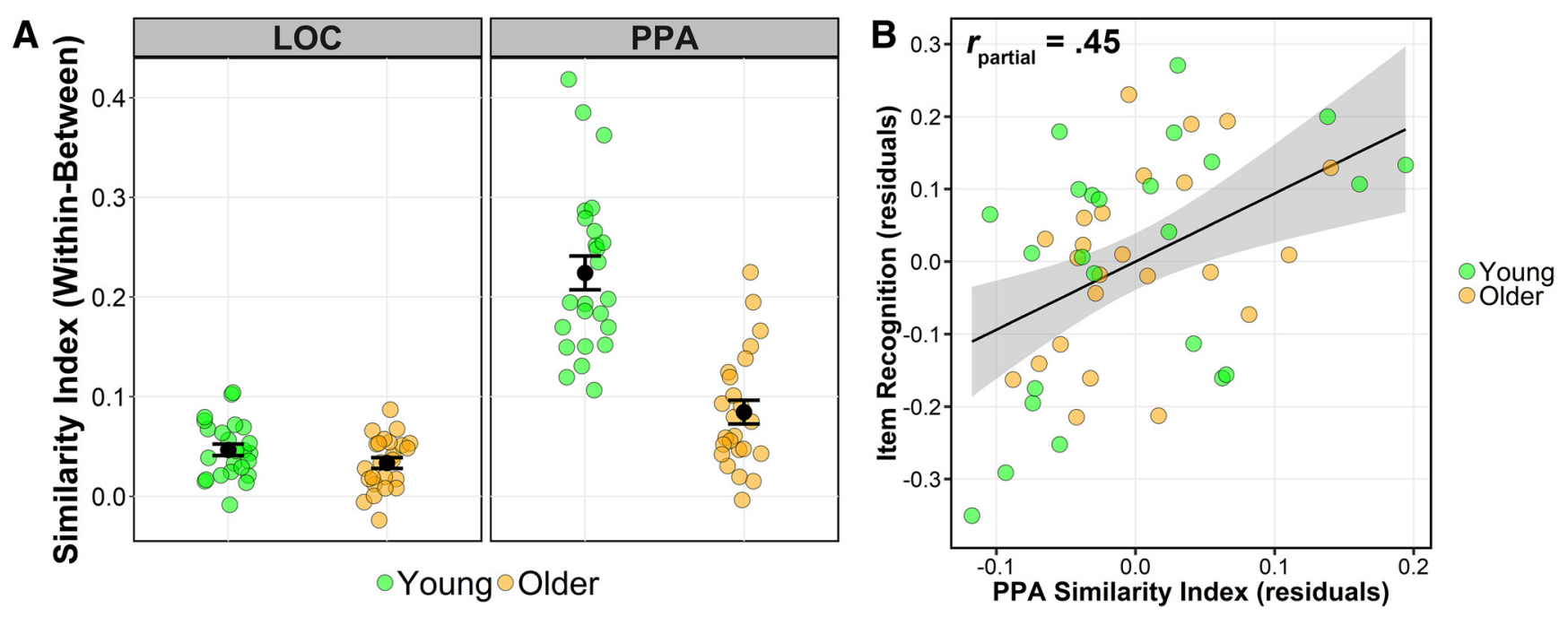

Figure 6. A, Plot of the similarity index (within-between similarity for the preferred image type) computed from the LOC and PPA for young and older adults. $\boldsymbol{B}$, Scatter plot showing the partial correlation between the similarity index in the PPA and item recognition controlling for age group.

A second account arises from the prosaic idea that perceptual experience and knowledge accumulate over the life span because of an ever-increasing number of encounters with new exemplars of different perceptual categories (for related findings showing that the neural correlates of object processing are moderated by a variable related to life experience, namely culture, see Goh et al., 2007; for review, see Goh and Park, 2009). Thus, when confronted with a novel exemplar, older individuals are arguably better able to assimilate it into a pre-existing representational structure (a perceptual "schema"; Gilboa and Marlatte, 2017) than are young adults, who have had less opportunity to develop such schemas. Consequently, with increasing age, perceptual processing of novel category exemplars will come to more closely resemble the processing afforded previously experienced exemplars. By this hypothesis, therefore, age-related neural dedifferentiation is not necessarily a detrimental consequence of increasing age.

This "lifetime experience hypothesis" accounts for two important aspects of the present data. First, it is consistent with our finding that age-related dedifferentiation in the PPA resulted from neural attenuation. According to the above hypothesis, the processing of novel exemplars of a visual category will more closely resemble the processing engaged by familiar exemplars in older adults than in younger adults. Thus, when first encountered, such stimuli might be expected to elicit smaller neural responses in older individuals, that is, to demonstrate "repetition suppression"- the much studied neural correlate of perceptual priming (Henson and Rugg, 2003; Gotts et al., 2012; Barron et al., 2016).

Second, the hypothesis provides an explanation for the absence of age-related neural dedifferentiation in the LOC reported here and previously (Chee et al., 2006), and its absence in wordand color-selective cortical regions in the study by Voss et al. (2008). The hypothesis predicts that age differences in neural differentiation will be diminished for exemplars that are similarly familiar to both young and older individuals. Arguably, even young adults have experienced canonical objects of the kinds used in the present study on numerous occasions before the experimental session, resulting in a blunting of age differences in neural differentiation. Consistent with this proposal, Voss et al. (2008) failed to identify age-related dedifferentiation for words, whereas Park et al. (2004) reported robust dedifferentiation for pseudowords, items that likely would not have been encountered by members of either age group pre-experimentally.

\section{Relationship between neural differentiation and memory performance}

We observed robust correlations between the PPA neural differentiation index and both recognition memory performance for the experimental items and a fluency factor derived from neuropsychological test scores (for related findings, see Park et al., 2010; Du et al., 2016; Berron et al., 2018). The finding that lower neural differentiation was predictive of poorer memory performance is broadly consistent with our pre-experimental hypothesis that dedifferentiation should impact memory encoding. Importantly, this relationship was age invariant and suggests that neural selectivity and item recognition are similarly coupled across much of the adult life span (Rugg, 2017). As suggested by a reviewer, our failure to find age differences in memory performance might have contributed to the failure to find a moderating effect of age on the relationships between neural differentiation and cognitive performance. While we cannot definitively rule out this possibility, we note that findings from prior studies indicate that null effects of age on a behavioral measure are not a precondition for finding age-invariant brain-behavior correlations (de Chastelaine et al., 2011, 2016; Wang et al., 2016; for related findings, see Du et al., 2016).

Another important result is the seemingly selective relationship between neural differentiation and item recognition. Although the correlation with recognition remained when source memory performance was controlled for, the reverse was not the case. Thus, neural differentiation was primarily a predictor of memory for the experimental items themselves, and not for their study contexts, possibly suggesting that the relationship between neural differentiation and memory performance is dependent on such factors as task demands. One might predict that a unique relationship between source memory performance and neural differentiation would have emerged had the studied scenes and objects been used as source features rather as test items.

As noted, we found an age-invariant relationship between neural differentiation and one of the latent factors-fluencyderived from neuropsychological test performance. In line with 
the study by Park et al. (2010), who described an analogous relationship between neural differentiation and fluid intelligence (in older adults only), the present finding suggests that neural differentiation may index not just the precision with which perceptual information is represented, but also broader aspects of neural efficiency. More generally, our findings that the relationships between neural differentiation and item memory performance and fluency were age invariant could be seen as a challenge to the view that neural dedifferentiation is a determinant of cognitive aging (Li et al., 2001; Park et al., 2010). This conclusion should be treated as provisional, however, until the present findings are replicated in larger and more diverse samples of participants.

\section{References}

Abdi H, Williams LJ (2008) Principal components analysis. In: Encyclopedia of ecology, Vol 2 (Jørgensen SE, Fath BD, eds), pp 2940-2949. Oxford: Elsevier.

Açłk A, Sarwary A, Schultze-Kraft R, Onat S, König P (2010) Developmental changes in natural viewing behavior: bottom-up and top-down differences between children, young adults and older adults. Front Psychol 1 :207. CrossRef Medline

Bailey IL, Lovie-Kitchin JE (2013) Visual acuity testing: from the laboratory to the clinic. Vision Res 90:2-9. CrossRef Medline

Baltes PB, Lindenberger U (1997) Emergence of a powerful connection between sensory and cognitive functions across the adult life span: a new window to the study of cognitive aging? Psychol Aging 12:12-21. CrossRef Medline

Barron HC, Garvert MM, Behrens TE (2016) Repetition suppression: a means to index neural representations using BOLD? Philos Trans R Soc Lond B Biol Sci 371:20150355. CrossRef Medline

Benton AL (1968) Differential behavioral effects in frontal lobe disease. Neuropsychologia 6:53-60. CrossRef

Berron D, Neumann K, Maass A, Schütze H, Fliessbach K, Kiven V, Jessen F, Sauvage M, Kumaran D, Düzel E (2018) Age-related functional changes in domain-specific medial temporal lobe pathways. Neurobiol Aging 65: 86-97. CrossRef Medline

Carp J, Park J, Hebrank A, Park DC, Polk TA (2011a) Age-related neural dedifferentiation in the motor system. PLoS One 6:e29411. CrossRef Medline

Carp J, Park J, Polk TA, Park DC (2011b) Age differences in neural distinctiveness revealed by multi-voxel pattern analysis. Neuroimage 56:736743. CrossRef Medline

Chee MW, Goh JO, Venkatraman V, Tan JC, Gutchess A, Sutton B, Hebrank A, Leshikar E, Park D (2006) Age-related changes in object processing and contextual binding revealed using fMR adaptation. J Cogn Neurosci 18:495-507. CrossRef Medline

Cohen J (1988) Statistical power analysis for the social sciences, Ed 2. Hillsdale, NJ: Erlbaum.

Craik FIM (1986) A functional account of age differences in memory. In: Human memory and cognitive capabilities: mechanisms and performance (Klix F, Hagendorf H, eds), pp 409-422. Amsterdam: Elsevier.

Craik FI, Rose NS (2012) Memory encoding and aging: a neurocognitive perspective. Neurosci Biobehav Rev 36:1729-1739. CrossRef Medline

de Chastelaine M, Wang TH, Minton B, Muftuler LT, Rugg MD (2011) The effects of age, memory performance, and callosal integrity on the neural correlates of successful associative encoding. Cereb Cortex 21:2166-2176. CrossRef Medline

de Chastelaine M, Mattson JT, Wang TH, Donley BE, Rugg MD (2016) The relationships between age, associative memory performance, and the neural correlates of successful associative memory encoding. Neurobiol Aging 42:163-176. CrossRef Medline

Delis DC, Kramer JH, Kaplan E, Ober BA (2000) California verbal learning test, Ed 2. San Antonio, TX: The Psychological Corporation.

Drag LL, Bieliauskas LA (2010) Contemporary review 2009: cognitive aging. J Geriatr Psychiatry Neurol 23:75-93. CrossRef Medline

Du Y, Buchsbaum BR, Grady CL, Alain C (2016) Increased activity in frontal motor cortex compensates impaired speech perception in older adults. Nat Commun 7:12241. CrossRef Medline

Epstein R, Kanwisher N (1998) A cortical representation of the local visual environment. Nature 392:598-601. CrossRef Medline
Ferris FL 3rd, Kassoff A, Bresnick GH, Bailey I (1982) New visual acuity charts for clinical research. Am J Ophthalmol 94:91-96. CrossRef Medline

Folstein MF, Folstein SE, McHugh PR (1975) Mini-mental state. J Psychiatr Res 12:189-198. CrossRef Medline

Friedman D, Johnson R (2014) Inefficient encoding as an explanation for age-related deficits in recollection-based processing. J Psychophysiol 28: 148-161. CrossRef

Gilboa A, Marlatte H (2017) Neurobiology of schemas and schemamediated memory. Trends Cogn Sci 21:618-631. CrossRef Medline

Goh JO, Park DC (2009) Culture sculpts the perceptual brain. Prog Brain Res 178:95-111. CrossRef Medline

Goh JO (2011) Functional dedifferentiation and altered connectivity in older adults: neural accounts of cognitive aging. Aging Dis 2:30-48. Medline

Goh JO, Chee MW, Tan JC, Venkatraman V, Hebrank A, Leshikar ED, Jenkins L, Sutton BP, Gutchess AH, Park DC (2007) Age and culture modulate object processing and object-scene binding in the ventral visual area. Cogn Affect Behav Neurosci 7:44-52. CrossRef Medline

Goh JO, Suzuki A, Park DC (2010) Reduced neural selectivity increases fMRI adaptation with age during face discrimination. Neuroimage 51: 336-344. CrossRef Medline

Gotts SJ, Chow CC, Martin A (2012) Repetition priming and repetition suppression: a case for enhanced efficiency through neural synchronization. Cogn Neurosci 3:227-237. CrossRef Medline

Grady CL, Maisog JM, Horwitz B, Ungerleider LG, Mentis MJ, Salerno JA, Pietrini P, Wagner E, Haxby JV, Gillette J, Giacometti K, Baldwin P, Jacobs G, Stein S, Green S, Fluck S, Der M (1994) Age-related changes in cortical blood flow activation during visual processing of faces and location. J Neurosci 14:1450-1462. CrossRef Medline

Grady CL, Charlton R, He Y, Alain C (2011) Age differences in fMRI adaptation for sound identity and location. Front Hum Neurosci 5:24. CrossRef Medline

Greenhouse SW, Geisser S (1959) On methods in the analysis of profile data. Psychometrika 24:95-112. CrossRef

Grill-Spector K, Kourtzi Z, Kanwisher N (2001) The lateral occipital complex and its role in object recognition. Vision Res 41:1409-1422. CrossRef Medline

Henson RN, Rugg MD (2003) Neural response suppression, haemodynamic repetition effects, and behavioural priming. Neuropsychologia 41: 263-270. CrossRef Medline

Hotelling H (1933) Analysis of a complex of statistical variables into principal components. J Educ Psychol 24:417-441. CrossRef

Hunt RR (1995) The subtlety of distinctiveness: what von Restorff really did. Psychon Bull Rev 2:105-112. CrossRef Medline

Johnson JD, McDuff SG, Rugg MD, Norman KA (2009) Recollection, familiarity, and cortical reinstatement: a multivoxel pattern analysis. Neuron 63:697-708. CrossRef Medline

Kaiser HF (1958) The varimax criterion for analytic rotation in factor analysis. Psychometrika 23:187-200. CrossRef

Kleemeyer MM, Polk TA, Schaefer S, Bodammer NC, Brechtel L, Lindenberger U (2017) Exercise-induced fitness changes correlate with changes in neural specificity in older adults. Front Hum Neurosci 11:123. CrossRef Medline

Koen JD, Yonelinas AP (2014) The effects of healthy aging, amnestic mild cognitive impairment, and Alzheimer's disease on recollection and familiarity: a meta-analytic review. Neuropsychol Rev 24:332-354. CrossRef Medline

Koen JD, Horne ED, Hauck N, Rugg MD (2018) Age-related differences in prestimulus subsequent memory effects assessed with event-related potentials. J Cogn Neurosci 30:829-850. CrossRef Medline

Kriegeskorte N, Mur M, Bandettini P (2008) Representational similarity analysis-connecting the branches of systems neuroscience. Front Syst Neurosci 2:4. CrossRef Medline

Kuznetsova A, Brockhoff PB, Christensen RHB (2015) lmerTest Package: tests in linear mixed effects models. J Stat Softw 82:1-26. CrossRef

Lenth RV (2016) Least-squares means: the R package lsmeans. J Stat Softw 69:1-33. CrossRef

Li SC, Sikström S (2002) Integrative neurocomputational perspectives on cognitive aging, neuromodulation, and representation. Neurosci Biobehav Rev 26:795-808. CrossRef Medline

Li SC, Lindenberger U, Sikström S (2001) Aging cognition: from neuro- 
modulation to representation. Trends Cogn Sci 5:479-486. CrossRef Medline

Liu P, Hebrank AC, Rodrigue KM, Kennedy KM, Section J, Park DC, Lu H (2013) Age-related differences in memory-encoding fMRI responses after accounting for decline in vascular reactivity. Neuroimage 78:415-425. CrossRef Medline

Lockhart RS, Craik FIM, Jacoby L (1976) Depth of processing, recognition and recall. In: Recall and recognition (Brown J, ed), pp 75-102. London, UK: Wiley.

Luo L, Hendriks T, Craik FI (2007) Age differences in recollection: three patterns of enhanced encoding. Psychol Aging 22:269-280. CrossRef Medline

Macmillan NA, Creelman CD (2005) Detection theory: a user's guide, Vol 2. Hillsdale, NJ: Erlbaum.

Mattson JT, Wang TH, de Chastelaine M, Rugg MD (2014) Effects of age on negative subsequent memory effects associated with the encoding of item and item-context information. Cereb Cortex 24:3322-3333. CrossRef Medline

McDuff SG, Frankel HC, Norman KA (2009) Multivoxel pattern analysis reveals increased memory targeting and reduced use of retrieved details during single-agenda source monitoring. J Neurosci 29:508-516. CrossRef Medline

Mumford JA, Davis T, Poldrack RA (2014) The impact of study design on pattern estimation for single-trial multivariate pattern analysis. Neuroimage 103:130-138. CrossRef Medline

Murdock BB Jr (1960) The distinctiveness of stimuli. Psychol Rev 67:16-31. CrossRef Medline

Old SR, Naveh-Benjamin M (2008) Differential effects of age on item and associative measures of memory: a meta-analysis. Psychol Aging 23:104118. CrossRef Medline

Park DC, Lautenschlager G, Hedden T, Davidson NS, Smith AD, Smith PK (2002) Models of visuospatial and verbal memory across the adult life span. Psychol Aging 17:299-320. CrossRef Medline

Park DC, Polk TA, Park R, Minear M, Savage A, Smith MR (2004) Aging reduces neural specialization in ventral visual cortex. Proc Natl Acad Sci U S A 101:13091-13095. CrossRef Medline

Park J, Carp J, Hebrank A, Park DC, Polk TA (2010) Neural specificity predicts fluid processing ability in older adults. J Neurosci 30:9253-9259. CrossRef Medline

Park J, Carp J, Kennedy KM, Rodrigue KM, Bischof GN, Huang CM, Rieck JR, Polk TA, Park DC (2012) Neural broadening or neural attenuation? Investigating age-related dedifferentiation in the face network in a large lifespan sample. J Neurosci 32:2154-2158. CrossRef Medline

Payer D, Marshuetz C, Sutton B, Hebrank A, Welsh RC, Park DC (2006) Decreased neural specialization in old adults on a working memory task. Neuroreport 17:487-491. CrossRef Medline

R Core Team (2017) R: a language and environment for statistical computing. Vienna, Austria: R Foundation.

Raven J, Raven JC, Courth JH (2000) Manual for Raven's progressive matrices and vocabulary scales. Section 4 : the advanced progressive matrices. San Antonio, TX: Harcourt Assessment.

Raz N, Rodrigue KM (2006) Differential aging of the brain: patterns, cognitive correlates and modifiers. Neurosci Biobehav Rev 30:730-748. CrossRef Medline

Raz N, Lindenberger U, Rodrigue KM, Kennedy KM, Head D, Williamson A, Dahle C, Gerstorf D, Acker JD (2005) Regional brain changes in aging healthy adults: general trends, individual differences and modifiers. Cereb Cortex 15:1676-1689. CrossRef Medline
Reitan RM, Wolfson D (1985) The Halstead-Reitan neuropsychological test battery: therapy and clinical interpretation. Tucson, AZ: Neuropsychological.

Revelle WR (2017) psych: procedures for psychological, psychometric, and personality research. Vienna, Austria: R Foundation.

Rissman J, Gazzaley A, D’Esposito M (2004) Measuring functional connectivity during distinct stages of a cognitive task. Neuroimage 23:752-763. CrossRef Medline

Rugg MD (2017) Interpreting age-related differences in memory-related neural activity. In: Cognitive neuroscience of aging: linking cognitive and cerebral aging, Ed 2 (Cabeza R, Nyberg L, Park DC, eds), pp 183-206. New York: Oxford UP.

Satterthwaite FE (1946) An approximate distriubtion of estimates of variance components. Biometrics 2:110-114. CrossRef Medline

Schoemaker D, Gauthier S, Pruessner JC (2014) Recollection and familiarity in aging individuals with mild cognitive impairment and Alzheimer's disease: a literature review. Neuropsychol Rev 24:313-331. CrossRef Medline

Singmann H, Bolker B, Westfall J, Aust F (2016) afex: analysis of factorial experiments. Vienna, Austria: R Foundation.

Smith A (1982) Symbol digit modalities test (SDMT) manual. Los Angeles: Western Psychological Services.

Snodgrass JG, Corwin J (1988) Pragmatics of measuring recognition memory: applications to dementia and amnesia. J Exp Psychol Gen 117:34-50. CrossRef Medline

Spencer WD, Raz N (1995) Differential effects of aging on memory for content and context: a meta-analysis. Psychol Aging 10:527-539. CrossRef Medline

Spreen O, Benton AL (1977) Neurosensory center comprehensive examination for aphasia. Victoria, BC, Canada: Neuropsychology Laboratory.

Spreng RN, Wojtowicz M, Grady CL (2010) Reliable differences in brain activity between young and old adults: a quantitative meta-analysis across multiple cognitive domains. Neurosci Biobehav Rev 34:1178-1194. CrossRef Medline

St-Laurent M, Abdi H, Bondad A, Buchsbaum BR (2014) Memory reactivation in healthy aging: evidence of stimulus-specific dedifferentiation. J Neurosci 34:4175-4186. CrossRef Medline

Voss MW, Erickson KI, Chaddock L, Prakash RS, Colcombe SJ, Morris KS, Doerksen S, Hu L, McAuley E, Kramer AF (2008) Dedifferentiation in the visual cortex: an fMRI investigation of individual differences in older adults. Brain Res 1244:121-131. CrossRef Medline

Wang TH, Johnson JD, de Chastelaine M, Donley BE, Rugg MD (2016) The effects of age on the neural correlates of recollection success, recollectionrelated cortical reinstatement, and post-retrieval monitoring. Cereb Cortex 26:1698-1714. CrossRef Medline

Wechsler D (1981) WAIS-R: Wechsler adult intelligence scale-revised. New York: The Psychological Corporation.

Wechsler D (2001) Wechsler test of adult reading. San Antonio, TX: The Psychological Corporation.

Wechsler D (2009) Wechsler memory scale, 4th ed. San Antonio, TX: The Psychological Corporation.

Xue G, Dong Q, Chen C, Lu Z, Mumford JA, Poldrack RA (2010) Greater neural pattern similarity across repetitions is associated with better memory. Science 330:97-101. CrossRef Medline

Zheng L, Gao Z, Xiao X, Ye Z, Chen C, Xue G (2018) Reduced fidelity of neural representation underlies episodic memory decline in normal aging. Cereb Cortex 28:2283-2296. CrossRef Medline 